\title{
Fundamental Concepts and Novel Aspects of Polycystic Ovarian Syndrome: Expert Consensus Resolutions
}

OPEN ACCESS

Edited by:

Daniele Santi,

University of Modena and Reggio

Emilia, Italy

Reviewed by:

Ljiljana Marina,

University of Belgrade, Serbia

Biagio Cangiano,

University of Milan, Italy

*Correspondence:

Alberto Ferlin

alberto.ferlin@unibs.it

Specialty section:

This article was submitted to Reproduction,

a section of the journal

Frontiers in Endocrinology

Received: 15 May 2020

Accepted: 26 June 2020

Published: 11 August 2020

Citation:

Aversa A, La Vignera S, Rago $R$, Gambineri A, Nappi RE, Calogero AE and Ferlin A (2020) Fundamental

Concepts and Novel Aspects of

Polycystic Ovarian Syndrome: Expert

Consensus Resolutions.

Front. Endocrinol. 11:516. doi: 10.3389/fendo.2020.00516

\section{Antonio Aversa ${ }^{1}$, Sandro La Vignera ${ }^{2}$, Rocco Rago ${ }^{3}$, Alessandra Gambineri ${ }^{4}$, Rossella E. Nappi ${ }^{5}$, Aldo E. Calogero ${ }^{2}$ and Alberto Ferlin ${ }^{6 *}$}

${ }^{1}$ Department of Experimental and Clinical Medicine, University "Magna Graecia", Catanzaro, Italy, ${ }^{2}$ Department of Clinical and Experimental Medicine, University of Catania, Catania, Italy, ${ }^{3}$ Physiopathology of Reproduction and Andrology Unit, Sandro Pertini Hospital, Rome, Italy, ${ }^{4}$ Department of Medical and Surgical Science, University Alma Mater Studiorum, Bologna, Italy, ${ }^{5}$ Research Center for Reproductive Medicine, Gynecological Endocrinology and Menopause, IRCCS San Matteo Foundation, University of Pavia, Pavia, Italy, ${ }^{6}$ Department of Clinical and Experimental Sciences, University of Brescia, Brescia, Italy

Polycystic ovary syndrome (PCOS) is a very common endocrine and metabolic disorder with the involvement of both genetic and environmental factors. Although much has been clarified on its pathogenesis, diagnosis, clinical manifestations, and therapy, there are still areas of uncertainty. To address fundamental concepts, novel aspects and hypotheses, and future perspectives, including the possible additional benefits of treatment with nutraceuticals, an expert consensus panel formed by endocrinologists and gynecologists was established. After an independent review of the literature, the panel convened electronically on February 3, 2020, and six resolutions were created, debated, and agreed upon discussion, and finally approved in their final form in a consensus livestream meeting held on April 15. The summary of the resolutions are: (1) PCOS is a well-established medical condition that negatively affects reproduction, general health, sexual health, and quality of life; (2) the symptoms and signs of PCOS appear early in life especially in female newborns from PCOS carriers; (3) women with PCOS have significantly increased risk of pregnancy-related complications including gestational diabetes mellitus; (4) a male PCOS equivalent exists, and it may impact on metabolic health and probably on reproduction; (5) the evidence supports that medical therapy for PCOS is effective, rational, and evidence-based; (6) the evidence supports a major research initiative to explore possible benefits of nutraceutical therapy for PCOS. The proposed resolutions may be regarded as points of agreement based on the current scientific evidence available.

Keywords: PCOS, medical therapy, nutraceuticals, PCOS carriers, male PCOS, consensus

\section{INTRODUCTION}

Polycystic ovary syndrome (PCOS) is a very common endocrine disorder in women of reproductive age, with a reported prevalence ranging from 6 to 15\% (1). Its etiology involves both genetic and environmental factors. Typically, women with PCOS show clinical and biochemical hyperandrogenism, oligoanovulation, and micropolycystic morphology of the ovaries (2). However, PCOS diagnosis relies on specific criteria that differ according to the scientific association that released them (Table 1). 
TABLE 1 | Criteria for the diagnosis of polycystic ovary syndrome (3).

\begin{tabular}{|c|c|c|}
\hline NIH/NICHD & ESHRE/ASRM 2004 & $\begin{array}{l}\text { Androgen Excess } \\
\text { Society } 2006\end{array}$ \\
\hline $\begin{array}{l}\text { Includes all of the } \\
\text { following criteria: }\end{array}$ & $\begin{array}{l}\text { Includes two of the following } \\
\text { criteria: }\end{array}$ & $\begin{array}{l}\text { Includes all of the } \\
\text { following criteria: }\end{array}$ \\
\hline $\begin{array}{l}\text { - Clinical and/or } \\
\text { biochemical signs of } \\
\text { hyperandrogenism }\end{array}$ & $\begin{array}{l}\text { - Clinical and/or } \\
\text { biochemical signs of } \\
\text { hyperandrogenism }\end{array}$ & $\begin{array}{l}\text { - Clinical and/or } \\
\text { biochemical signs of } \\
\text { hyperandrogenism }\end{array}$ \\
\hline $\begin{array}{l}\text { - Menstrual } \\
\text { dysfunction }\end{array}$ & $\begin{array}{l}\text { - Oligo-ovulation or } \\
\text { anovulation } \\
\text { - Polycystic ovaries }\end{array}$ & $\begin{array}{l}\text { - Ovarian dysfunction } \\
\text { and/or polycystic } \\
\text { ovaries }\end{array}$ \\
\hline
\end{tabular}

ESHRE/ASRM, European Society for Human Reproduction and Embryology/American Society for Reproductive Medicine; NIH/NICHD, National Institutes of Health/National Institute of Child Health and Human Development.

The diagnostic criteria do not consider the widely recognized dysmetabolic background of PCOS. Indeed, many patients have impaired insulin action [up to $75 \%$ of them are insulinresistant (IR)], hyperinsulinemia, and overweight/obesity, and this appears to play a crucial role in the pathogenesis of PCOS. Two major PCOS phenotypes can be distinguished: the overweight/obese and the lean one. Their estimated prevalence is $\approx 80$ and $\approx 20 \%$, respectively (4). Insulin resistance is a fundamental pathogenic component of PCOS, both in lean and overweight-obese patients. The expression of the syndrome differs between lean and overweight-obese PCOS. Worryingly, some patients with the lean phenotype may not show symptoms such as irregular menses or acne $(5,6)$, and this increases the chance of underdiagnosis or misdiagnosis. Women with PCOS are exposed to metabolic alterations, endothelial dysfunction, and cardiovascular risk factors, independently from obesity, even if obesity aggravates the phenotype (7). Therefore, a timely diagnosis and proper management should be warranted.

Although much has been clarified in recent years on the pathogenesis, diagnosis, clinical manifestations, and therapy of PCOS, there are still many doubts and consequent uncertainties in the choice of the therapeutic approach in clinical practice.

To address some important concerns of PCOS and especially its possible treatment with nutraceuticals, a panel of Italian experts convened webinar on February 3, 2020, after an independent review of the literature. The panel included clinicians dealing with this condition such as endocrinologists and gynecologists. Six resolutions were proposed, debated, and agreed on after a thorough discussion. Then the resolutions were written, discussed in their final version, and approved in a final consensus webinar held on April 15.

The summary of the resolutions and the condensed expert opinions are reported in Table 2.

\section{Resolution 1: PCOS is a Well-Established Medical Condition That Negatively Affects Reproduction, General Health, Sexual Health, and Quality of Life}

Polycystic ovary syndrome is the most frequent disorder in women of reproductive age, and it is also one of the most well-studied. Nevertheless, many unresolved questions regarding its pathogenesis, diagnosis, clinical manifestations, acute and chronic complications, and treatment are still debated (8). It is one of the most common causes of menstrual irregularities, such as amenorrhea, oligomenorrhea, and polymenorrhea, and is the primary cause of anovulatory infertility (9). Infertility is aggravated by a high percentage of miscarriages, as well as by low pregnancy and live birth rates after assisted reproductive technologies (ARTs) (5). In addition, women with PCOS tend to produce a greater number of oocytes during ART and to have higher rates of ovarian hyperstimulation syndrome and/or multiple gestations compared with non-PCOS infertile women (5). Furthermore, increased pregnancy complications and obstetric and neonatal risks are also associated with PCOS. These include gestational diabetes mellitus (GDM), preeclampsia, pregnancy-induced hypertension, postpartum hemorrhage and infection, preterm delivery, meconium aspiration, stillbirth, operative deliveries, and shoulder dystocia (5, 10, 11). The presence of obesity exacerbates all these complications and produces a blunted responsiveness to ovulation induction in proportion to its severity and, particularly, when the abdominal phenotype of obesity (visceral fat accumulation) is present (12-15).

The pathophysiological mechanisms by which PCOS negatively impacts on fertility are complex and not completely understood. Undoubtedly, hyperandrogenism, the consequent hyperestrogenemia, IR, and compensatory hyperinsulinemia play an important role acting on both the ovary and the endometrium (16-19). In addition, there is emerging evidence that proinflammatory cytokines and oxidative stress may directly impact on oocyte quality and may induce endothelial dysfunction, thus contributing to infertility $(6,12,13)$. Some recent ex vivo and in vivo studies have also demonstrated that proinflammatory cytokines inhibit follicle-stimulating hormone (FSH) and luteinizing hormone (LH) receptor expression, thus impairing the regular follicular development and its luteinization. They also inhibit FSH-induced $17 \beta$-estradiol and progesterone secretion from granulosa cells obtained by preovulatory follicles and stimulate testosterone production from theca cells, all mechanisms that contribute to impair ovulation and, therefore, infertility (20-22).

Polycystic ovary syndrome is not only a reproductive endocrinopathy, but it is also a metabolic endocrinopathy, for the high prevalence of overweight/abdominal obesity, dyslipidemia, non-alcoholic fatty liver disease (NAFLD), type 2 diabetes mellitus (T2DM), and metabolic syndrome (MetS) $(4,23,24)$. Obesity, hyperandrogenism, and IR are known risk factors for increasing NAFLD and T2DM occurrence in PCOS (20, 25, 26). Furthermore, these metabolic alterations are wellknown additional risk factors for cardiovascular diseases (CVDs), although strong evidence in PCOS is lacking. Additionally, chronic low-grade inflammation is a risk factor for IR and T2DM (16, 27-29). In addition, many recent studies have clearly shown that PCOS is associated with anxiety (30-36) and depression $(26-32,37,38)$, and with a poorer quality of life $(27,32,34,39-42)$, even in adolescence and young age (43). Both physical and mental distress may contribute to 
TABLE 2 | Summary of resolutions and expert opinion.

Resolution Condensed expert opinion

1 PCOS is a well-established medical condition that negatively affects reproduction, general health, sexual health, and quality of life.

- PCOS is a multifaceted disease with an impact on various aspects of a woman's life, such as aesthetics, reproduction, metabolism, psychological well-being, and sexuality.

- Phenotypization is fundamental for providing a tailored therapy.

2 The symptoms and signs of PCOS appear early in life especially in female newborns from PCOS carriers.

- Daughters of PCOS women inherit certain characteristics that become more evident across puberty.

- Early recognition of PCOS in adolescence is fundamental to set up individualized strategies to ameliorate symptoms and to counteract reproductive and metabolic risks associated with this condition.

3 Women with PCOS have significantly increased risk of pregnancy-related complications including gestational diabetes.

- Women with PCOS have an increased risk of GDM than controls, especially if obesity/metabolic syndrome are present, and should be carefully investigated and monitored during early pregnancy with OGTT.

- Changes in intestinal microbiota during pregnancy may contribute to the onset of metabolic dysfunction in both the mother and the offspring.

4 A male PCOS equivalent seems to exist, and it may impact on metabolic health and probably on reproduction.

- Male PCOS equivalent may be diagnosed in presence of PCOS-like hormonal pattern, metabolic abnormalities, overweight/obesity, and/or clinical signs of hyperandrogenism, above all in patients aged $<35$ years with a family history positive for PCOS.

- The metabolic and hormonal profile should be assessed in first-degree male relatives of PCOS women and in men with early-onset AGA. This may help to prevent the risk of T2DM and CVD later in life.

- Further studies are needed to confirm the existence of a male PCOS equivalent and to evaluate its impact on the testicular function.

5 The evidence supports that medical therapy for women with PCOS is effective, rational, and evidence-based.

- No single unified treatment for PCOS is available, and treatment should be individualized.

- Targets for pharmacological treatment include biochemical and clinical androgen excess, menstrual irregularities, anovulation, insulin resistance, and metabolic profile.

- Lifestyle counseling should be provided in all cases.

- COCPs are the first-line treatment for long-term management of menstrual irregularities and hyperandrogenism.

- Metformin should be recommended in overweight/obese adult PCOS women and considered in adolescents with PCOS for the management of weight, insulin resistance, and metabolic abnormalities.

6 The evidence supports a major research initiative to explore possible benefits of nutraceutical therapy for PCOS.

- $\mathrm{MI}$ and DCl show different insulin-mimetic properties. Inositol administration should be aimed to keep unaltered the $\mathrm{MI} / \mathrm{DCl}$ ratio.

- Treatment with MI/ALA combination may ameliorate hyperinsulinemia, decrease oxidative stress markers at oocyte level, and normalize endometrial inflammasome in PCOS women with idiopathic recurrent pregnancy loss.

- The hormonal and clinical profile of overweight/obese women with PCOS may benefit from prolonged use of MI/ALA combination, such as a higher recovery of class II oocytes during ART.

- NAFLD may be associated with PCOS. A timely diagnosis is warranted to avoid the NAFLD-related long-term complications. A nutraceutical approach could be useful in the treatment of NAFLD.

- Hyperomocysteinemia may be associated with selected PCOS patients. Treatment with folic acid should be started to avoid the long-term consequences on the cardiovascular system.

- Nutraceuticals, associated with diet and lifestyle modifications, can be important therapeutic option to manage pregnancy-related complications in PCOS pregnant patients.

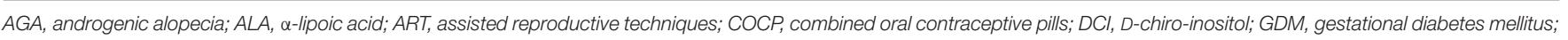
MI, myoinositol; NAFLD, non-alcoholic fatty liver disease; OGTT, oral glucose tolerance test; T2DM, type 2 diabetes mellitus.

decrease the quality of life in PCOS $(36,44,45)$ regardless of body mass index (BMI), hyperandrogenism, and socioeconomic status (33). However, the presence of obesity, menstrual disorders, clinical hyperandrogenism (acne, alopecia, hirsutism), and infertility may impact on the quality of life $(26,31$, 34, 35, 46-49). Thus, infertility and hirsutism have been associated with both anxiety $(26,27,50)$ and depression $(29,46)$ and alopecia with anxiety (23), whereas obesity and acne with depression $(26,31,34)$. Accordingly, both weight loss and oral contraceptive use significantly improve several physical and mental domains related to quality of life, depressive symptoms, and anxiety disorders $(51,52)$. A high percentage of eating disorders, such as anorexia nervosa, bulimia nervosa, and binge eating disorder, have also been observed in PCOS $(29,53)$, particularly in the presence of anxiety and depression (49). 
More contradictory results have been found regarding the association between PCOS and sexual dysfunctions, because some studies described a high prevalence of sexual dysfunctions $(38,46,49,54-56)$, whereas others did not $(35,57-64)$. The studies that have demonstrated a high prevalence (46, 5053) described defect in arousal, poor lubrification (46) and pain during intercourse $(52,53)$, and high degree of sexual dissatisfaction $(38,50-52)$. All the aspects of sexual dysfunction described in PCOS are exacerbated by the presence of obesity (42, $50,51,61,65)$, alopecia, and infertility, regardless of its duration (53). Contradictory results have been described regarding the association between sexual dysfunction and androgen circulating levels, with some studies demonstrating a positive correlation (50), others negative $(61,66)$, whereas others show no significant association (60). Hirsutism $(38,64)$, acne (67), and a sense of low attractiveness $(38,51)$ resulted mostly associated with low sexual satisfaction. As expected, PCOS women with the lowest sexual satisfaction exhibited an even stronger predilection toward anxiety and depression than the other women $(34,50,51)$.

Altogether, these data demonstrate that PCOS is appropriately defined syndrome for the complexity and heterogeneity of the clinical manifestations, associated comorbidities, and clinical consequences that accompany the woman during reproductive and postreproductive age, thus impacting on the quality of life.

\section{Expert Opinion}

- Polycystic ovary syndrome is a multifaceted disease with an impact on various aspects of women's life, such as aesthetics, reproduction, metabolism, psychological wellbeing, and sexuality.

- The lean PCOS phenotype has a high risk of underdiagnosis and misdiagnosis with respect to the overweight/obese phenotype.

- The phenotypization of the woman with PCOS is fundamental for providing a tailored therapy, by taking advantage of the wide and diversified therapeutic availability.

\section{Resolution 2: The Symptoms and Signs of PCOS Appear Early in Life Especially in Female Newborns From PCOS Carriers}

Nowadays, PCOS is a lifelong medical condition requiring a multispecialist vision for early diagnosis and an effective management and treatment plan over time (10). Preconception care, mainly in infertility clinics, is the golden moment to identify PCOS carriers because PCOS-like outcomes, especially in female offspring, result from both genetic and epigenetic mechanisms $(68,69)$. Indeed, specific PCOS-susceptibility loci may explain family predisposition and the variable clinical presentation of PCOS, including neuroendocrine, reproductive, and metabolic abnormalities (70). On the other hand, maternalfetal interactions account for early signs of hyperandrogenism in offspring of PCOS carriers, resulting not only from heritability, but also from the intrauterine androgen excess of maternal and/or fetal origin, with the contribution of a dysfunctional placenta (71). Overexposure to androgens in utero influences the activity of multiple pathways regulating gonadotropin-releasing hormone $(\mathrm{GnRH})$ pulsatility, follicular development, ovarian steroidogenesis, and insulin-glucose homeostasis (72).

Glucose intolerance and hyperinsulinemia in metabolically unhealthy PCOS mothers further contribute to the prenatal hyperandrogenic milieu, which plays a leading role in reprogramming female offspring for reproductive, behavioral, and metabolic PCOS-like traits with some gender differences (73). On the other hand, injuries to the fetoplacental unit deriving from gestational-related conditions, such as hypertension and/or T2DM, or unhealthy habits (smoking, lack of exercise, etc.) may have an influence on weight at birth reprogramming metabolic function even in offspring of mothers without PCOS (74).

During infancy and adolescence, this "metabolic memory" may likely induce a non-genetic inheritance of PCOS-like features, linked to overweight and/or abdominal obesity, which are still preventable with healthy habits (adequate diet, active lifestyle, etc.) $(8,75)$. Altogether, endocrine and metabolic events in intrauterine life become evident early postnatally (76) and may give origin to a high rate of overt signs and symptoms of PCOS manifesting at puberty and progressing with age (77). Apart from subtle signs of a compromised cardiometabolic health, predominantly in female offspring (76) the diagnosis of PCOS in mothers and/or elevated fetal testosterone has been also linked to pervasive developmental disabilities, autism spectrum disorder, and attention-deficit/hyperactivity disorder, an evidence recently confirmed in a US cohort of infants of PCOS mothers (78).

Polycystic ovary syndrome diagnosis during infancy and childhood is virtually impossible because symptoms are missing. However, the measurement of anti-Müllerian hormone (AMH), a surrogate marker of ovarian hyperandrogenism produced by small antral follicles (79), in daughters of women with PCOS may represent a reliable proxy. Indeed, AMH values are higher across puberty and correlate with $\mathrm{LH}$ and testosterone plasma levels, indicating multifollicular ovarian morphology resulting from enhanced recruitment, decreased depletion or even from follicular growing arrest, and reduced rate of atresia $(18,80)$. Newborns with low and high birth weights have higher $\mathrm{AMH}$ levels than normal birth weight infants tested at 2-3 months of age (81). However, body weight abnormalities at birth do not seem associated with having a PCOS mother (82). On the other hand, birth weight and thinness at birth independently predict symptoms of PCOS in adulthood (83). Many coexisting elements, such as maternal obesity, pregnancy complications, and other comorbidity make it difficult to identify the real contribution of PCOS mothers to health and development of offspring (84).

In any case, it is more likely that daughters of PCOS women have more abdominal fat distribution and signs of hyperandrogenism compared with control daughters across pubertal maturation (85). Increased glucose-stimulated insulin levels are also a consistent phenotype in the daughters of women with PCOS in mid to late puberty (86). Moreover, $5 \alpha-$ reductase, the key enzyme in androgen metabolism, catalyzing the irreversible conversion of testosterone to dihydrotestosterone (DHT) into the skin, is significantly increased during early childhood in daughters of women with PCOS (87). On the other 
hand, IR per se amplifies hyperandrogenic signs by enhancing the activity of $5 \alpha$-reductase at the target levels (88).

Even though no causal relationship between excessive adiposity and early puberty has been clearly demonstrated, it is likely that these girls can accelerate their growth and maturation in a homeostatic attempt to reduce their abdominal obesity, showing a higher tendency to early pubarche and eventually early menarche (89). On the other hand, an excess of adipose tissue during adolescence undoubtedly increases the possibility of developing multifollicular ovarian morphology resembling PCOS-like aspect. This is also a sign of reproductive axis immaturity, and therefore, it is not considered a diagnostic criterion within 2 years after menarche. Irregular menses that persist 2 years after menarche may be a sign of PCOS, although they may continue up to the fifth year after menarche without developing PCOS. Circulating androgens reach adult levels generally by age 15 years, and hirsutism may increase progressively over the time (90). In adolescence, IR and hyperinsulinemia have a widespread impact on reproductive function by multiple mechanisms, including a synergic role with LH to stimulate the secretion of androgens from the ovarian theca. Moreover, insulin, by lowering liver sex hormone-binding globulin (SHBG) production, increases androgen bioavailability at target organs, further contributing to clinical signs of hyperandrogenism (91).

Finally, IR, independently from the extent of obesity and magnitude of androgen concentrations, may be present even in lean PCOS. However, transient hyperinsulinemia is typical at puberty and may amplify the individual predisposition to develop PCOS (92).

Collectively, these data indicate that clinical signs of hyperandrogenism observed in adolescent PCOS, in particular acne, are likely influenced not only by the abundance of DHT at the level of the pilosebaceous unit, but also by different abnormal insulin signaling in concert with nutritional aspects (93). Symptoms of androgen excess may be quite common in adolescents and may cause significant distress well before a final diagnosis of PCOS can be formulated. To ameliorate hyperandrogenic signs, it is essential to find therapeutic strategies to fill the gap between the physiological changes of puberty and the clear clinical picture that becomes evident some years following menarche (94). Therefore, knowing that an intergenerational risk for PCOS exists serves to prevent its onset from intrauterine to adult life.

\section{Expert Opinion}

- Polycystic ovary syndrome is a clear example of transgenerational disease that results from genetic and epigenetic mechanisms from prenatal life to adulthood.

- Daughters of women with PCOS inherit certain characteristics that become more evident across puberty. These include abdominal fat distribution and signs of hyperandrogenism.

- Early recognition of PCOS in adolescence is fundamental to set up individualized strategies to ameliorate symptoms and to counteract reproductive and metabolic risks associated with this condition.

\section{Resolution 3: Women With PCOS Have Significantly Increased Risk of Pregnancy-Related Complications Including Gestational Diabetes}

Polycystic ovary syndrome is a primary risk factor for adverse pregnancy outcomes. A meta-analysis conducted by Kjerulff et al. (95) indicated that pregnancy in PCOS patients is associated with increased risk of GDM, pregnancy-induced hypertension, preeclampsia, preterm delivery, and small-for-gestational age, and according to various data, the risk of miscarriage in PCOS women is reported to be three times higher than in healthy women (96). Indeed, PCOS could be included as a risk factor for GDM (97).

During pregnancy, a physiologic insulin insensitivity occurs because of the release of placental hormones. These hormones promote nutrient utilization by the fetus, but on the other hand, IR associated with pregnancy is the main pathogenic mechanism leading the development of GDM in predisposed women such as PCOS. All lipoprotein subclasses and lipids are markedly increased in pregnant women, and the most pronounced differences are observed for the intermediatedensity, low-density (LDL), and high-density lipoprotein (HDL) triglyceride concentrations (98). All these metabolic alterations lead to an increase in the plasma concentration of circulating proinflammatory cytokines, such as tumor necrosis factor $\alpha$ and interleukin 6 (IL-6), with reduction of plasma anti-inflammatory molecule levels such as adiponectin and IL-10 (99). Furthermore, inflammatory mediator overexpression, together with an increase of reactive oxygen species (ROS), could lead to metabolic alterations and vascular disease and induce inhibition of the insulin signaling pathway, thus resulting in IR, reduced insulin gene expression, and, consequently, reduced $\beta$-cell insulin secretion and GDM (100). In many cases, these factors are already present in women with PCOS, and therefore pregnancy can be the final hit in the onset of DM.

According to the current Italian guidelines on GDM, PCOS women carrying high risk (i.e., obesity, previous macrosomia or GDM, fasting blood sugar $100-125 \mathrm{mg} / \mathrm{dL}$ at the beginning of pregnancy) should be investigated by oral glucose tolerance test (OGTT) between the 16th and 18th week of gestation and, if normal, by repeating it between the 24th and 28th week of pregnancy (101).

A crucial role of the intestinal microbiota in pregnancyrelated GDM has been suggested. In the first trimester, the composition of the gut microbiota is similar to that of a non-pregnant woman. In the following months, the variability of microorganisms decreases, and there is an increase in the populations of Proteobacteria and Actinobacteria; Bifidobacteria belong to the latter and play a pivotal role in the defense against pathogenic bacteria, in strengthening the intestinal barrier, and in the nutrients' metabolism. The intestine of a pregnant woman can become more permeable favoring the so-called "bacterial translocation" so that the fetus can come into contact with microorganisms of maternal origin (microbes have been found in the blood of the umbilical cord, in the amniotic fluid, and even in the meconium) (102-104). Furthermore, according to 
the most widespread theories, the baby's intestine is colonized during childbirth by the bacteria of the maternal microbiota. If the pregnant woman is in dysbiosis, the fetus will not receive bifid but other bacterial strains, which could lead to a greater exposure of the newborn to diseases. This imbalance can also lead to a greater absorption of calories with a consequent weight increase of the pregnant woman and a greater risk of developing GDM. Even the newborn could more easily develop childhood diabetes, allergies, and childhood obesity (102-104).

\section{Expert Opinion}

- Women with PCOS have an increased risk of GDM than controls, especially if obesity/MetS are present, and should be carefully investigated and monitored during early pregnancy with OGTT.

- Changes in intestinal microbiota during pregnancy may contribute to the onset of metabolic dysfunction in both the mother and the offspring.

\section{Resolution 4: A Male PCOS Equivalent Seems to Exist, and it May Impact on Metabolic Health and Probably on Reproduction}

The genetic background of PCOS (105) suggests the existence of a male PCOS equivalent (106). Indeed, even male relatives inherit the same genetic factors predisposing to female PCOS. However, little is known about the putative presence of a male-PCOS and its possible consequences in men.

Kinship of PCOS women has an increased risk to develop metabolic abnormalities and CVDs, independently of the gender. Indeed, their siblings have a higher prevalence of IR, hyperinsulinemia, dyslipidemia, and hypertension already at a young age ( $<40$ years) (107-109). Young first-degree male relatives have endothelial dysfunction that is not present in female PCOS patients (110). Therefore, the male relatives have an increased metabolic and cardiovascular risk. Furthermore, obesity, MetS, T2DM, and CVDs are more frequently diagnosed in male and female first-degree relatives of PCOS women compared to those with a negative PCOS family history $(107,108)$.

Only few studies have explored hormonal abnormalities in the first-degree male relatives of women with PCOS. They have been shown to have higher dehydroepiandrosterone (DHEAS) level $(111,112)$, which suggests the presence of a similar steroidogenic abnormality reported in their sisters. In addition, they have higher levels of $\mathrm{AMH}, \mathrm{LH}$, and FSH compared with controls (113). Moreover, a higher $\mathrm{LH}$ and FSH response to $\mathrm{GnRH}$ stimulation test has been reported in these men compared to controls (114), suggesting the presence of an abnormal GnRHinduced gonadotropin release.

The presence of metabolic, cardiovascular, and hormonal alterations in the male relative of women with PCOS supports the existence of a male PCOS equivalent. Accordingly, several authors have shown the occurrence of early-onset ( $<35$ years) androgenetic alopecia (AGA) [grade $\geq$ III, Hamilton-Norwood scale $(115,116)]$ in male relatives of PCOS women $(117,118)$.
Therefore, early-onset AGA has been proposed as a clinical sign of the male PCOS equivalent. On this account, the hormonal and metabolic pattern has been evaluated in men with earlyonset AGA, independently from the kinship with PCOS women. A meta-analysis carried out in 1,009 unrelated men showed increased LH and DHEAS, decreased SHBG, a downward trend for $\mathrm{FSH}$, and an upward trend for the $\mathrm{LH} / \mathrm{FSH}$ ratio in patients with early-onset AGA compared with controls (119), therefore resembling the female PCOS hormonal pattern. The same meta-analysis found a significant increase of insulin levels and Homeostatic Model Assessment (HOMA) index, total and LDL cholesterol, and triglycerides in patients with respect to controls, already before the age of 35 years. Unfortunately, there are no data on the reproductive function in men with early-onset AGA. Although it is plausible that the reproductive potential of subjects with "male PCOS phenotype" might be compromised similarly to women with PCOS, one could also speculate that fertility could be even improved in these subjects, highlighting therefore an intriguing evolutionary paradox.

By contrast, a large amount of data has been produced on the metabolic, cardiovascular, and prostatic sequelae in aging men with early-onset AGA. A hospital-based analysis reported a higher risk for myocardial infarction in 665 patients with respect to 772 controls; the risk was higher for severe vertex [Relative risk(RR), 3.4] compared with frontal AGA (RR, 0.9) (120). A retrospective study carried out in 22,071 men aged 4084 years found an increased prevalence of T2DM in patients with severe vertex AGA than those belonging to other hair-pattern categories (121). Moreover, the Framingham Study showed a positive correlation between AGA progression and coronary heart disease (CHD) (122). The NHANES I Epidemiologic Follow-up Study (3,932 men aged 25-73 years) reported that severe AGA was positively associated with mortality for CHD in men before 55 years of age (123). Furthermore, a metaanalysis on 29,254 participants confirmed the positive correlation between AGA and CHD, IR, hyperinsulinemia, and MetS in both genders (124). The level of the evidence is high enough that AGA has been already proposed as an independent predictor of mortality for T2DM and CVDs (125). Finally, prostate inflammation, hyperplasia, and even cancer have been reported in men with early-onset AGA (120). Current evidence supports a relationship between prostate inflammation and hyperplasia with IR and hyperinsulinemia, whose mechanisms are not clear yet. It might be speculated that prostate diseases represent longterm consequence of male PCOS equivalent, whose pathogenesis includes metabolic abnormalities.

In conclusion, PCOS syndrome is not simply a primarily ovarian disorder, because the core of its pathogenesis is a metabolic dysfunction, as also suggested by the long-term complications found in these patients. The genetic predisposition to develop a syndrome with a negative impact on metabolism can occur also in men. Current evidence indicates the existence of metabolic, cardiovascular, and hormonal abnormalities in the first-degree males of PCOS women. The higher prevalence of early-onset AGA found in these men supports that it may represent a phenotypic feature of the male PCOS equivalent. Accordingly, patients with early-onset AGA show a PCOS-like 
hormonal pattern, increased insulin, HOMA index, total and LDL cholesterol, and triglycerides compared to age-matched controls. Similar to female PCOS, long-term consequences of early-onset AGA (male PCOS equivalent) include T2DM, CVDs, and a higher mortality for CHD. Hence, the male PCOS syndrome might be defined as an endocrine syndrome with a metabolic background predisposing to the development of T2DM, CVDs, and prostatic diseases later in life.

\section{Expert Opinion}

- Male PCOS equivalent may be diagnosed in presence of PCOS-like hormonal pattern (increased DHEAS, AMH, LH, $\mathrm{LH} / \mathrm{FSH}$ ratio, high calculated free testosterone), metabolic abnormalities (IR, hyperinsulinemia, low SHBG levels, hyperglycemia), overweight/obesity, and/or clinical signs of hyperandrogenism (mainly early-onset AGA), above all in patients younger than 35 years with a family history positive for PCOS.

- The metabolic and hormonal profile should be assessed in first-degree male relatives of PCOS women and in men with early-onset AGA. This may help to prevent the risk of T2DM and CVD later in life.

- Further studies are needed to confirm the existence of a male PCOS equivalent and to evaluate its impact on the testicular function.

\section{Resolution 5: Evidence Supports That Medical Therapy for Women With PCOS is Effective, Rational, and Evidence-Based}

Pharmacological treatments commonly used in women with PCOS are off-label because neither the Food and Drug Administration nor the European Medicines Agency has ever approved a specific drug for PCOS treatment. However, they are widely used and their efficacy is evidence-based and rational (74).

Therapeutic approaches aim to improve disease-related symptoms and should therefore target hyperandrogenism, the consequences of ovarian dysfunction (menstrual irregularities, infertility), and/or the associated metabolic disorders. Apart from ovulation induction and treatment of infertility and topicalaesthetic therapies for hirsutism and acne, pharmacological treatment is recommended when the first-line approach represented by lifestyle modifications (diet and/or physical activity) is not able alone to ameliorate the symptoms and signs of PCOS. The evidence for medical therapy of PCOS is summarized in a recent report from 37 societies and organizations that published the first international evidence-based guideline for the assessment and management of PCOS (94).

Combined oral contraceptive pills (COCPs) are first-line pharmacological management for menstrual irregularity and hyperandrogenism, whereas metformin (alone or in addition to COCPs) is recommended for the management of metabolic alterations associated with PCOS $(52,126)$. The rational and efficacy of COCPs treatment are linked to their ability to decrease the pulse frequency of GnRH (and therefore the secretion of FSH and $\mathrm{LH}$ ), the ability of progestin combined to lack of estrogen positive feedback to suppress midcycle LH surge and LH levels (and thus ovarian androgen production), and to the ability of different estrogen-progestin combinations to increase SHBG, thereby reducing bioavailable free androgens. Also, some progestins have antiandrogenic properties, because of their antagonizing effects on the androgen receptor and to the inhibition of $5 \alpha$-reductase activity.

Combined oral contraceptive pills exert a class effect on PCOS. However, in order to reduce the thromboembolic risk, the lowest effective estrogen doses (such as 20-30 $\mu \mathrm{g}$ of ethinylestradiol) or the use of natural estradiol should be preferred. Even though clinical trials (127) almost always use COCPs containing antiandrogen progestins (due to higher effect on hyperandrogenism symptoms), the guidelines do not recommend a specific progestin. A recent meta-analysis showed that COCPs containing cyproterone acetate are more effective in suppressing gonadotropins, leading to a decrease in androgen levels (128). Another meta-analysis showed that COCPs containing drospirenone have a more potent effect than COCPs containing chlormadinone acetate in the reduction of circulating androgen-related hirsutism (129). A risk-benefit assessment should take place when selecting a specific COCPs in the individual woman to minimize potential metabolic and thromboembolic consequences. Indeed, third-generation and antiandrogenic progestins are the drugs of choice for hirsutism, alopecia, and acne, but may carry higher risks as compared to the second generation. In combination with COCPs, antiandrogens-considering their potential hepatotoxicity and other side effects-should only be considered in PCOS when androgen-related alopecia and/or hirsutism have to be treated, after 6 months or more failure of COCPs and cosmetic therapy (130). Antiandrogens must be used with effective contraception, to avoid male fetal undervirilization.

Metformin, in addition to lifestyle changes, should be recommended in adult women with BMI $\geq 25 \mathrm{~kg} / \mathrm{m}^{2}$ and considered in adolescents with PCOS for the management of weight (131) and metabolic abnormalities. It is most beneficial in high metabolic risk groups including patients with T2DM risk factors or impaired glucose tolerance and non-obese IR PCOS women; it should be started at a low dose (with 500-mg increments 1-2 weekly), using extendedrelease preparations, to minimize gastrointestinal side effects. Conclusive data suggest that metformin alone has benefits for adult women for management of weight, hormonal (testosterone), and metabolic outcomes (fasting glucose and insulin, LDL cholesterol), especially for women with $\mathrm{BMI} \geq 25$ $\mathrm{kg} / \mathrm{m}^{2}$, whereas COCPs are more effective than metformin for menstrual regulation, and metformin combined with COCPs may be useful for the management of metabolic features (95). Finally, there is reliable evidence regarding the use of metformin for anthropometric (reduction of body weight and decrease of waist) outcomes and COCPs for hyperandrogenism in women with PCOS (132). In fact, in overweight women with PCOS, metformin plus lifestyle changes might be the best intervention to improve IR and total triglycerides, whereas COCPs plus lifestyle changes appear to be the best intervention for the reduction of total cholesterol and LDL cholesterol, therefore suggesting a combined treatment with metformin and COCPs in these patients (133). 
A recent meta-analysis (134) suggested that orlistat, an antiobesity drug that decreases fat absorption from the intestine, is more effective than metformin in weight loss, LDL and cholesterol level, and IR. Another meta-analysis aimed at evaluating the efficacy and safety of glucagon-like peptide 1 (GLP-1) receptor agonists showed that GLP-1 receptor agonists were more effective than metformin in improving insulin sensitivity and reducing BMI, suggesting that GLP-1 receptor agonists might be a good choice for obese patients with PCOS, especially those with IR (135). However, for both orlistat and GLP-1 receptor agonists, the available evidence is of low quality and therefore inconclusive.

\section{Expert Opinion}

- No single unified treatment for PCOS is available. Treatment should be individualized and adapted to the patient. Treatment should aim to improve those symptoms and signs that represent the patient's real needs and can be changed over time.

- Targets for pharmacological treatment include biochemical and clinical androgen excess, menstrual irregularities, anovulation, insulin resistance, and metabolic profile.

- Lifestyle counseling should be provided in all cases given the deleterious effects of abdominal adiposity and obesity on the cardiometabolic risk profile.

- Combined oral contraceptive pills should be used as a first-line treatment for long-term management of menstrual irregularities and hyperandrogenism.

- No specific COCPs are recommended. However, those containing the lowest effective doses of estrogens (20-30 $\mu \mathrm{g}$ ethinylestradiol) or preparations with natural estrogens should be preferred.

- Combined oral contraceptive pills containing an antiandrogenic progestin are the drugs of choice for hirsutism, alopecia, and acne.

- Metformin should be recommended in overweight/obese adult PCOS women and considered in adolescents and lean IR PCOS women for the management of weight, IR, and metabolic abnormalities.

\section{Resolution 6: Evidence Supporting the Possible Benefits of Nutraceutical Therapy in PCOS}

Several nutraceuticals have been investigated for their possible benefits in the management of PCOS-related IR, anovulation, liver inflammation and hyperhomocysteinemia. They include inositols, $\alpha$-lipoic acid (ALA), silybin, resveratrol, vitamin D, vitamin E, and folic acid, whose evidences are summarized in the following resolution.

Myoinositol (MI) and D-chiro-inositol (DCI) are both implicated in the modulation of insulin signaling on steroid and ovarian folliculogenesis. In recent years, several studies have shown their effectiveness in patients with PCOS (136). The choice of the inositol to be prescribed to women with PCOS should be guided as much as possible by an evidence-based background. Both MI and DCI show insulin-mimetic properties and decrease postprandial blood glucose, but display a different peripheral action (137). Particularly, DCI acts on glycogen synthesis at the level of the skeletal muscle (138) by up-regulating GLUT4 expression (130). Myoinositol is involved in glucose uptake and FSH signaling in the ovary, whereas DCI influences the insulindependent synthesis of androgens (139). Epimerase converts MI into DCI in an insulin-sensitive manner and IR dramatically reduces the amount of epimerization (140) leading to a deficiency of DCI-dependent insulin-sensitive properties in PCOS patients. In human ovaries, $\sim 99 \%$ of the intracellular pool of inositol is constituted of MI, and the remaining part of DCI $(132,141)$. An imbalance in the ovarian concentration between MI and DCI can compromise the FSH pulsatility rate so that we highlight the importance of keeping unaltered the MI/DCI ratio, rather than restoring only one of the two inositols $(142,143)$.

Recent therapeutic evidence addressed the importance of the association between ALA and MI or DCI. $\alpha$-Lipoic acid is a powerful antioxidant and enzymatic cofactor of the mitochondrial respiratory chain, in turn, capable of increasing insulin sensitivity. It is believed to directly scavenge ROS and reactive nitrogen species (RNS), both in vitro and in vivo. $\alpha$ Lipoic acid regenerates essential antioxidant molecules, that is, coenzyme Q10, vitamin C, vitamin E, and chelates several heavy metals involved in oxidative processes. Also, ALA can repair oxidative stress-damaged proteins, lipids, and DNA (144). Also, it is supposed to improve glycemic control due to the ALAinduced GLUT-4 expression with subsequent uptake of glucose within tissues (145). Also, systematic review and meta-analysis suggested that ALA might be able to decrease serum leptin (146) concentrations especially in younger adults depending on the longer time of assumption; also, a significant increase in serum levels of adiponectin in studies, which lasted for more than 8 weeks (146). $\alpha$-Lipoic acid possibly decreases both adipose tissue leptin and circulating leptin mRNA levels through enhanced peroxisome proliferator-activated receptor- $\gamma$ activity, which has an important role in decreasing leptin gene expression and in determining appropriate insulin signaling (147). This effect may be considered important given a recent meta-analysis suggesting that ALA decreased body weight among participants with obesity; therefore, it might be possible that ALA by AMPK activation and weight reduction decreases leptin and increases adiponectin levels $(146,148)$, thus representing a very promising molecule in reducing some frequent features of PCOS, that is, increased body weight and inflammation (145).

Several studies support the use of ALA $(149,150)$ for its direct and indirect antioxidant effects through the regeneration of other antioxidants and its anti-inflammatory activities exerted by inhibiting some cytokines. Some authors have shown that the endometrial inflammasome, in which prevails the overexpression/activation of NALP-3, is associated with idiopathic recurrent pregnancy loss (RPL) and that the combined treatment can re-modulate the endometrial pathway of NALP3 with a decrease of the concentrations of apoptotic cytokines (151). In a group of PCOS patients, treatment with ALA and DCI led to a non-significant improvement of clinical and metabolic features, that is, insulin, BMI, HDL, and menstrual cyclicity, compared to an untreated control group (152). Masharani and colleagues highlighted the benefits of ALA on glucose uptake in lean PCOS patients, although this evidence is limited by the 
poor number of patients treated (153). In the pilot cohort study by De Cicco and colleagues, 40 patients with normoinsulinemic overweight PCOS were treated for 6 months with the MI plus ALA combination and the results showed a decrease in $\mathrm{BMI}$, waist-hip ratio, hirsutism score, $\mathrm{AMH}$, ovarian volume, and antral follicle count, and an increase in the number of menstrual cycles (from 2 to 5) (154). Genazzani and colleagues demonstrated that the combined administration of ALA and MI to obese PCOS women, grouped by the presence or absence of familiarity with type 1 or T2DM, led to an improvement of insulin sensitivity in patients with T2DM familiarity and an improvement in the insulin response to OGTT in both groups, unlike what was observed after treatment with MI alone (155).

In PCOS women with familiarity for T2DM and therefore with a reduced expression of lipoic acid synthase and epimerase, the combination of ALA plus MI markedly reactivated the stimulus on GLUT4 and therefore was able to improve insulin sensitivity (156). Also, the treatment with ALA (400 mg/d) improved the metabolic features especially in the presence of T2DM. Numerous evidence show that the treatment with MI and/or DCI improves reproductive outcomes in terms of spontaneous induction of ovulation and leads to a modification of the standard treatments used for ART, that is, a reduction in either the gonadotropin units required for the controlled ovarian hyperstimulation $(\mathrm{COH})$ or in the overall number of days required to reach the maximal stimulation (157). At the same time, an improvement in oocyte quality and pregnancy rate has been observed both in humans (158-161) and in animal models (162). A randomized trial evaluated the effects of MI alone or in combination with ALA in a population of non-obese PCOS women undergoing ART. Significant reductions in BMI, insulin (baseline and after OGTT), ovarian volume, and gonadotropin units used for $\mathrm{COH}$ were observed. The oocyte quality was inversely correlated with the decrease of the BMI, resulting in a greater recovery of M-II oocytes, the formation of classes I and II embryos, and the increase in the pregnancy rate (163).

Evidence has shown the role of nutraceuticals in treating NAFLD. Silybin seems effective to treat PCOS-related NAFLD, which is defined as the clustering of triglycerides in macroor micro-vesicles in more than $5 \%$ of hepatocytes. NAFLD is frequently present in PCOS women, with a diagnosis rate of up to $40 \%$ in the lean phenotype (164) and nearly $50 \%$ of obese PCOS women (165). It may develop into cirrhosis and hepatic failure, and therefore, its identification and treatment are of importance in patients with PCOS. A large body of in vitro evidence supports the direct benefit of incubation with silybin on hepatocytes in NAFLD models, mainly due to its capacity to reverse lipid accumulation in the liver (166-168). A controlled study in 90 NAFLD patients and 30 healthy controls reported the effectiveness of 6-month administration of silybin, vitamin $\mathrm{D}$, and vitamin $\mathrm{E}$ on NAFLD fibrosis score, metabolic markers, oxidative stress, and endothelial dysfunction (169). Finally, the use of the polyphenol resveratrol is associated with the reduction of circulating tryglicerides (170). Altogether these preliminary reports suggest that the role of nutraceuticals in the treatment of PCOS may be extended to NAFLD, though focused randomized controlled trials (RCTs) need to be accomplished.

Hyperhomocysteinemia occurs in some patients with PCOS, in particular in those with a greater metabolic derangement (women with IR or hyperinsulinemia) (171). A genomic study evaluated the effect of the G2706A and G1051A polymorphisms of the $A B C A 1$ gene on homocysteine serum levels in a cohort of 98 PCOS patients and 93 healthy controls. Significantly higher homocysteine levels were found in PCOS patients with the ABCA G1051A mutant genotype than heterozygotes or wild type (172). Interestingly, among patients with PCOS, homocysteine levels may predict pregnancy outcome, being higher in PCOS patients with recurrent pregnancy loss compared with fertile PCOS controls (173). Hyperhomocysteinemia predicts the risk of developing atherosclerosis in patients with MetS (174) and it is a risk factor for ischemic heart disease and stroke (175). A metaanalysis has shown that folic acid lowers the risk of stroke by $10 \%$ and of overall CVD by $4 \%$ in patients with hyperomocysteinemia (176). This evidence justify the assessment of homocysteine and its possible treatment in PCOS patients.

Diet and healthy lifestyles are universally recognized treatments for obesity and IR before and during pregnancy in PCOS women (177). Remarkably, in most countries, none of the oral hypoglycemic agents are allowed during the gestational period and insulin remains the only therapeutic option to manage GDM. However, in the last years, in a variety of experimental models, inositol and antioxidant supplementation have shown insulin-sensitizing, anti-inflammatory, and antioxidant properties, providing an important therapeutic opportunity for women with PCOS and GDM (178, 179). On the other hand, combined inositol treatment improves blood pressure, glucose, and leptin levels in pregnant women with metabolic-like syndrome phenotype (180). Promising data from RCTs of MI dietary supplementation have shown positive results in terms of ameliorating IR, the incidence of GDM, and its adverse outcomes (181). Interesting studies report that MI can prevent the development of GDM by improving glucose metabolism in PCOS patients (126, 182). In this condition, a diet rich in fat-soluble vitamins, fiber, and antioxidants may play a positive role (183). For example, chronic consumption of quercetin, a flavonoid antioxidant, seems to alleviate fasting and postprandial hyperglycemia in animal models of DM, in part by inhibiting $\alpha$-glucosidase activity (184). $\alpha$-Lipoic acid as a supplemental agent has recently been proposed in T2DM, obesity, and pregnancies complicated by GDM (156). $\alpha$-Lipoic acid can decrease either glycemic or inflammation levels especially in dysmetabolic patients with an increased T2DM risk occurrence (144). A recent meta-analysis indicated that it decreases body weight and leptin levels and increases adiponectin levels in obese participants (146). Other antioxidants, such as epigallocatechin 3-gallate, vitamin E, and resveratrol, have been suggested to have similar effects (170). Vitamin D replacement may have some beneficial effects on IR (185).

Finally, a meta-analysis of 11 RCTs including 719 pregnant women with GDM recently analyzed the effect of a 4 - to 8 -week-long probiotic administration on pregnancy outcome, 
glycemic control, blood lipid profile, inflammation, and oxidative stress. Lactobacillus and Bifidobacterium were prescribed in almost all RCTs. Probiotic administration resulted in a lower risk of offspring's hyperbilirubinemia. The authors also found the significant improvement of maternal glycemia, lipid profile, inflammation, and oxidative stress (186). In conclusion, inositols, ALA, vitamins, antioxidant supplementation, and multiple combinations of these compounds, associated with diet and lifestyle modifications, can be an important therapeutic option to manage PCOS and pregnancy-related complications. Evaluation of the safety of these compounds and their combinations concludes that they are safe, and there is no evidence of adverse events both in mothers and fetuses (187).

\section{Expert Opinion}

- Myoinositol and DCI show different insulin-mimetic properties. Inositol administration should be aimed to keep unaltered the MI/DCI ratio.

- Treatment with MI/ALA combination may ameliorate hyperinsulinemia, decrease oxidative stress markers at oocyte level, and normalize endometrial inflammasome in PCOS women with idiopathic recurrent pregnancy loss.

- The hormonal and clinical profile of overweight/obese women with PCOS may benefit from prolonged use of MI/ALA combination, such as a higher recovery of class II oocytes during ART.

- Non-alcoholic fatty liver disease may be associated with PCOS. A timely diagnosis is warranted to avoid the NAFLD-related long-term complications. A nutraceutical approach could be useful in the treatment of NAFLD.

- Hyperhomocysteinemia may be associated with selected PCOS patients. Treatment with folic acid should be started to avoid the long-term consequences on the cardiovascular system.

- Nutraceuticals, associated with diet and lifestyle modifications, can be important therapeutic option to manage pregnancyrelated complications in PCOS pregnant patients.

- Gut microbiota integrity is important to prevent pregnancyrelated complications in PCOS women.

\section{DISCUSSION}

Polycystic ovary syndrome is a clinically heterogeneous syndrome. Given the wide range of available therapeutic choices, it is important to recognize the exact phenotype (8) to provide the best evidence-based approach. Fetal exposure to a hyperinsulinemic and hyperandrogenic uterine environment leads to epigenetic changes (82) that, in addition to the genetic background, confer the susceptibility of developing a metabolic derangement in the offspring (male and female) of PCOS women. This represents the rational basis to look for PCOS early in life, allowing a timely diagnosis already in adolescence. Women with PCOS are exposed to an increased metabolic (and, probably, cardiovascular) risk later in life (7). Also, still in the youth, PCOS women have a higher risk of developing GDM compared to their counterparts, and therefore, proper counseling has to be made in those women who wish to become pregnant (97). Interestingly, the evidence pointed out to the possible existence of a male PCOS equivalent (106), which, similarly to the classic female phenotype (119), deserves to be early detected to avoid its long-term cardiometabolic (125) and, possibly, reproductive complications.

Several therapeutic choices are currently available for the management of PCOS women. The assessment of anthropometric data, biochemical and clinical androgen excess, menstrual irregularities, oligoanovulation, IR, and metabolic profile are required to adopt the best effective therapeutic strategy (52). Therapeutic options range from lifestyle changes (48) and aesthetic interventions to nutraceuticals and, finally, medications. Lifestyle counseling is required for a proper PCOS management in all patients. Although no specific COCP is recommended, this document suggests a prescription of the lowest effective estrogen doses (74). Those containing neutral/antiandrogenic progestin or antiandrogens should be preferred in the case of hirsutism, alopecia, and acne (130). Metformin should be recommended in overweight/obese adult PCOS women and considered in adolescents with PCOS for the management of weight, IR, and metabolic abnormalities. Furthermore, metformin may be an option to improve fertility, especially in IR overweight PCOS women.

Nutraceutical therapy seems to represent a challenge for the treatment of IR-PCOS women, with particular attention to restoring the MI/DCI ratio, which is unbalanced because of the insulin-dependent epimerase dysregulation, especially in obese patients (140), and possible usefulness of ALA. Many other supplemental elements are also available for the treatment of additional PCOS features, such as NAFLD or hyperomocysteinemia. However, further unbiased RCTs should be warranted to provide evidence-based data on the correct use of nutraceutical and appropriate timing in different phenotypes of PCOS patients.

This expert panel strongly encourages well-performed RCTs focused on analyzing the uncovered issues related to the application of nutraceuticals in these patients.

\section{AUTHOR CONTRIBUTIONS}

All authors contributed to conceptualization, methodology, bibliographic search and literature review, original draft preparation, review, editing, and have read and agreed to the published version of the manuscript.

\section{FUNDING}

The authors declare that this study received funding from Uriach Srl. The funder was not involved in the study design, collection, analysis, interpretation of data, the writing of this article or the decision to submit it for publication.

\section{ACKNOWLEDGMENTS}

Rossella Cannarella (Catania), Rosita A. Condorelli (Catania), Alessandro Dal Lago (Rome), Paolo Facondo (Brescia), Arianna Novellis (Bologna), Letizia Pezzaioli (Brescia), Giulia Stincardini (Pavia), Lara Tiranini (Pavia), Margherita Vergine (Catanzaro). 


\section{REFERENCES}

1. Yu HF, Chen HS, Rao DP, Gong J. Association between polycystic ovary syndrome and the risk of pregnancy complications: a PRISMAcompliant systematic review and meta-analysis. Medicine. (2016) 95:e4863. doi: 10.1097/MD.0000000000004863

2. Van Hooff MH, Voorhorst FJ, Kaptein MB, Hirasing RA, Koppenaal C, Schoemaker J. Predictive value of menstrual cycle pattern, body mass index, hormone levels and polycystic ovaries at age 15 years for oligo-amenorrhoea at age 18 years. Hum Reprod. (2004) 19:383-92. doi: 10.1093/humrep/deh079

3. Goodman NF, Cobin RH, Futterweit W, Glueck JS, Legro RS, Carmina E. American association of clinical endocrinologists, American college of endocrinology, and androgen excess and PCOS society disease state clinical review: guide to the best practices in the evaluation and treatment of polycystic ovary syndrome Part 2. Endocr Pract. (2015) 21:141526. doi: 10.4158/EP15748.DSCPT2

4. Toosy S, Sodi R, Pappachan JM. Lean polycystic ovary syndrome (PCOS): an evidence-based practical approach. J Diabetes Metab Disord. (2018) 17:27785. doi: 10.1007/s40200-018-0371-5

5. Nestler JE, Jakubowicz DJ. Lean women with polycystic ovary syndrome respond to insulin reduction with decreases in ovarian P450c17 alpha activity and serum androgens. J Clin Endocrinol Metab. (1997) 82:40759. doi: $10.1210 /$ jc. 82.12 .4075

6. Doh E, Mbanya A, Kemfang-Ngowa JD, Dohbit S, Tchana-Sinou M, Foumane $\mathrm{P}$, et al. The relationship between adiposity and insulin sensitivity in african women living with the polycystic ovarian syndrome: a clamp study. Int J Endocrinol. (2016) 2016:9201701. doi: 10.1155/2016/9201701

7. Sprung VS, Jones H, Pugh CJ, Aziz NF, Daousi C, Kemp GJ, et al. Endothelial dysfunction in hyperandrogenic polycystic ovary syndrome is not explained by either obesity or ectopic fat deposition. Clin Sci. (2014) 126:67-74. doi: 10.1042/CS20130186

8. Conway G, Dewailly D, Diamanti-Kandarakis E, Escobar-Morreale HF, Franks S, Gambineri A, et al. ESE PCOS special interest group. The polycystic ovary syndrome: a position statement from the European society of endocrinology. Eur J Endocrinol. (2014) 171:P1-29. doi: 10.1530/EJE-14-0253

9. Usadi RS, Legro RS. Reproductive impact of polycystic ovary syndrome. Curr Opin Endocrinol Diabetes Obes. (2012) 19:5050511. doi: 10.1097/MED.0b013e328359ff92

10. Fauser BC, Tarlatzis BC, Rebar RW, Lergo RS, Balen AH, Lobo R, et al. Consensus on women's health aspects of polycystic ovary syndrome (PCOS): the amsterdam ESHRE/ASRM-Sponsored 3rd PCOS consensus workshop group. Fertil Steril. (2012) 97:28-38.e25. doi: 10.1016/j.fertnstert.2011.09.024

11. Palomba S, Falbo A, Daolio J, Battagila FA, La Sala GB. Pregnancy complications in infertile patients with polycystic ovary syndrome: updated evidence. Minerva Ginecol. (2018) 70:754-60. doi: 10.23736/S0026-4784.18.04230-2

12. Pasquali R, Gambineri A, Pagotto U. The impact of obesity on reproduction in women with polycystic ovary syndrome. Br J Obstet Gynecol. (2006) 113:1148-59. doi: 10.1111/j.1471-0528.2006.00990.x

13. Balen AH, Conway GS, Kaltsas G, Techatrasak K, Manning PJ, West C, et al. Polycystic ovary syndrome: the spectrum of the disorder in 1741 patients. Hum Reprod. (1995) 10:210711. doi: 10.1093/oxfordjournals.humrep.a136243

14. Pasquali R, Patton L, Gambineri A. Obesity and infertility. Curr Opin Endocrinol Diabetes Obes. (2007) 14:4827. doi: 10.1097/MED.0b013e3282f1d6cb

15. Jungheim ES, Lanzendorf SE, Odem RR, Moley KH, Chang AS, Ratts VS, et al. Morbid obesity is associated with lower clinical pregnancy rates after in vitro fertilization in women with polycystic ovary syndrome. Fertil Steril. (2009) 92:256-61. doi: 10.1016/j.fertnstert.2008.04.063

16. Gambineri A, Laudisio D, Marocco C, Radellini S, Colao A, Savastano S, et al. Obesity programs of nutrition, education, research and assessment (OPERA) group. Female infertility: which role for obesity? Int J Obes Suppl. (2019) 9:65-72. doi: 10.1038/s41367-019-0009-1

17. Ferreira SR, Motta AB. Uterine function: from normal to polycystic ovarian syndrome alterations. Curr Med Chem. (2018) 25:1792-804. doi: 10.2174/0929867325666171205144119
18. Rosenfield RL, Ermann DA. The pathogenesis of polycystic ovary syndrome (PCOS): the hypothesis of PCOS as functional ovarian hyperandrogenism reivisted. Endocr Rev. (2016) 37:467-520. doi: 10.1210/er.2015-1104

19. Astapova O, Minor BMN, Hammes SR. Physiological and pathological androgen actions in the ovary. Endocrinology. (2019) 160:1166-74. doi: 10.1210/en.2019-00101

20. Popovic M, Sartorius G, Christ-Crain M. Chronic low-grade inflammation in polycystic ovary syndrome: is there a (patho)physiological role for interleukin-1? Semin Immunopathol. (2019) 41:447-59. doi: 10.1007/s00281-019-00737-4

21. Shorakes S, Teede H, DeCourten B, Lambert G, Boyle J, Moran LJ. The emerging role of chronic low-grade inflammation in the pathophysiology of polycystic ovary syndrome. Semin Reprod Med. (2015) 33:25769. doi: 10.1055/s-0035-1556568

22. Repaci A, Gambineri A, Pasquali R. The role of low-grade inflammation in the polycystic ovary syndrome. Mol Cell Endocrinol. (2011) 335:3041. doi: $10.1016 /$ j.mce.2010.08.002

23. Gambineri A, Repaci A, Patton L, Grassi I, Pocognoli P, Cognigni GE, et al. Prominent role of low HDL-cholesterol in explaining the high prevalence of the metabolic syndrome in polycystic ovary syndrome. Nutr Metab Cardiovasc Dis. (2009) 19:797-804. doi: 10.1016/j.numecd.2009.01.007

24. Gambineri A, Patton L, Altieri P, Pagotto U, Pizzi C, Manzoli L, et al. Polycystic ovary syndrome is a risk factor for type 2 diabetes: results from a long-term prospective study. Diabetes. (2012) 61:236974. doi: $10.2337 / \mathrm{db} 11-1360$

25. Pasquali R, Gambineri A. Glucose intolerance states in women with the polycystic ovary syndrome. J Endocrinol Invest. (2013) 36:64853. doi: 10.1007/BF03346757

26. Rocha ALL, Faria LC, Guimarães TCM, Moreira GV, Cândido AL, Couto $\mathrm{CA}$, et al. Non-alcoholic fatty liver disease in women with polycystic ovary syndrome: systematic review and meta-analysis. J Endocrinol Invest. (2017) 40:1279-88. doi: 10.1007/s40618-017-0708-9

27. Ojeda-Ojeda M, Martinez-García MÁ, Alpanés M, Luque-Ramírez M, Escobar-Morreale HF. Association of TLR2 S450S and ICAM1 K469E polymorphisms with polycystic ovary syndrome (PCOS) and obesity. $J$ Reprod Immunol. (2016) 113:9-15. doi: 10.1016/j.jri.2015.09.072

28. Donath MY. Targeting inflammation in the treatment of type 2 diabetes: time to start. Nat Rev Drug Discov. (2014) 13:465-76. doi: 10.1038/nrd4275

29. Jager J, Grémeaux T, Cormont M, Le Marchand-Brustel Y, Tanti JF. Interleukin-1beta-induced insulin resistance in adipocytes through downregulation of insulin receptor substrate-1 expression. Endocrinology. (2007) 148:241-51. doi: 10.1210/en.2006-0692

30. Chaudhari AP, Mazumdar K, Mehta PD. Anxiety, depression, and quality of life in women with polycystic ovarian syndrome. Indian J Psychol Med. (2018) 40:239-46. doi: 10.4103/IJPSYM.IJPSYM_561_17

31. Tan J, Wang Q-Y, Feng G-M, Li XY, Huang W. Increased risk of psychiatric disorders in women with polycystic ovary syndrome in southwest China. Chin Med J. (2017) 130:262-6. doi: 10.4103/0366-6999.198916

32. Ozcan Dag Z, Alpua M, Isik Y, Buturak SV, Tulmac OB, Turkel $\mathrm{Y}$. The evaluation of temperament and quality of life in patients with polycystic ovary syndrome. Gynecol Endocrinol. (2017) 33:2503. doi: $10.1080 / 09513590.2016 .1254610$

33. Annagür BB, Kerimoglu ÖS, Tazegül A, Gündüz S, Gençoglu BB. Psychiatric comorbidity in women with polycystic ovary syndrome. J Obstet Gynaecol Res. (2015) 41:1229-33. doi: 10.1111/jog.12696

34. Deeks AA, Gibson-Helm ME, Paul E, Teede HJ. Is having polycystic ovary syndrome a predictor of poor psychological function including anxiety and depression? Hum Reprod Oxf Engl. (2011) 26:1399-407. doi: 10.1093/humrep/der071

35. Cinar N, Kizilarslanoglu MC, Harmanci A, Aksoy DY, Bozdag G, Demir $\mathrm{B}$, et al. Depression, anxiety and cardiometabolic risk in polycystic ovary syndrome. Hum Reprod. (2011) 26:3339-45. doi: 10.1093/humrep/der338

36. Scaruffi E, Gambineri A, Cattaneo S, Turra J, Vettor R, Mioni R. Personality and psychiatric disorders in women affected by polycystic ovary syndrome. Front Endocrinol. (2014) 5:185. doi: 10.3389/fendo.2014.00185

37. Çoban ÖG, Tulaci ÖD, Adanir AS, Önder A. Psychiatric disorders, selfesteem, and quality of life in adolescents with polycystic ovary syndrome. J Pediatr Adolesc Gynecol. (2019) 32:600-4. doi: 10.1016/j.jpag.2019.07.008 
38. Stapinska-Syniec A, Grabowska K, Szpotanska-Sikorska M, Pietrzak B. Depression, sexual satisfaction, and other psychological issues in women with polycystic ovary syndrome. Gynecol Endocrinol. (2018) 34:597600. doi: 10.1080/09513590.2018.1427713

39. Shafti V, Shahbazi S. Comparing sexual function and quality of life in polycystic ovary syndrome and healthy women. J Fam Reprod Health. (2016) 10:92-98.

40. Karjula S, Morin-Papunen L, Franks S, Auvinen J, Järvelin MR, Tapanainen JS, et al. Population-based data at ages 31 and 46 show decreased HRQoL and life satisfaction in women with PCOS symptoms. J Clin Endocrinol Metab. (2020) 105:1814-26. doi: 10.1210/clinem/dgz256

41. Rzonca E, Bien A, Wdowiak A, Szymanski R, Iwanowicz-Palus G. Determinants of quality of life and satisfaction with life in women with polycystic ovary syndrome. Int J Environ Res Public Health. (2018) 15:376. doi: 10.3390/ijerph15020376

42. Panico A, Messina G, Lupoli GA, Lupoli R, Cacciapuoti M, Moscatelli F, et al. Quality of life in overweight (obese) and normal-weight women with polycystic ovary syndrome. Patient Prefer Adherence. (2017) 11:4239. doi: 10.2147/PPA.S119180

43. Guidi J, Gambineri A, Zanotti L, Fanelli F, Fava GA, Pasquali R. Psychological aspects of hyperandrogenic states in late adolescent and young women. Clin Endocrinol. (2015) 83:872-8. doi: 10.1111/cen.12783

44. Shishehgar F, Ramezani Tehrani F, Mirmiran P, Hajian S, Baghestani AR. Comparison of the association of excess weight on health related quality of life of women with polycystic ovary syndrome: an age- and bmi-matched case control study. PLoS ONE. (2016) 11:e0162911. doi: 10.1371/journal.pone.0162911

45. Coffey S, Bano G, Mason HD. Health-related quality of life in women with polycystic ovary syndrome: a comparison with the general population using the polycystic ovary syndrome questionnaire (PCOSQ) and the short form-36 (SF-36). Gynecol Endocrinol. (2006) 22:80-86. doi: 10.1080/09513590600604541

46. Kogure GS, Ribeiro VB, Lopes IP, Furtado CLM, Kodato S, Silva de Sá MF, et al. Body image and its relationships with sexual functioning, anxiety, and depression in women with polycystic ovary syndrome. J Affect Disord. (2019) 253:385-93. doi: 10.1016/j.jad.2019.05.006

47. Angin P, Yoldemir T, Atasayan K. Quality of life among infertile PCOS patients. Arch Gynecol Obstet. (2019) 300:4617. doi: 10.1007/s00404-019-05202-Z

48. Behboodi Moghadam Z, Fereidooni B, Saffari M, Montazeri A. Polycystic ovary syndrome and its impact on Iranian women's quality of life: a population-based study. BMC Womens Health. (2018) 18:164. doi: 10.1186/s12905-018-0658-1

49. Benetti-Pinto CL, Ferreira SR, Antunes A, Yela DA. The influence of body weight on sexual function and quality of life in women with polycystic ovary syndrome. Arch Gynecol Obstet. (2015) 291:4515. doi: 10.1007/s00404-014-3423-1

50. Asik M, Altinbas K, Eroglu M, Karaahmet E, Erbag G, Ertekin H, et al. Evaluation of affective temperament and anxiety-depression levels of patients with polycystic ovary syndrome. J Affect Disord. (2015) 185:2148. doi: 10.1016/j.jad.2015.06.043

51. Dokras A, Sarwer DB, Allison KC, Milman L, Kris-Etherton PM, Kunselman $\mathrm{AR}$, et al. Weight loss and lowering androgens predict improvements in health-related quality of life in women with PCOS. J Clin Endocrinol Metab. (2016) 101:2966-74. doi: 10.1210/jc.2016-1896

52. Harris-Glocker M, Davidson K, Kochman L, Guzick D, Hoeger K. Improvement in quality-of-life questionnaire measures in obese adolescent females with polycystic ovary syndrome treated with lifestyle changes and oral contraceptives, with or without metformin. Fertil Steril. (2010) 93:101619. doi: 10.1016/j.fertnstert.2009.08.006

53. Lee I, Cooney LG, Saini S, Smith ME, Sammel MD, Allison KC, et al. Increased risk of disordered eating in polycystic ovary syndrome. Fertil Steril. (2017) 107:796-802. doi: 10.1016/j.fertnstert.2016. 12.014

54. Hashemi S, Ramezani Tehrani F, Farahmand M, Bahri Khomami M. Association of PCOS and its clinical signs with sexual function among Iranian women affected by PCOS. J Sex Med. (2014) 11:250814. doi: $10.1111 /$ jsm. 12627
55. Månsson M, Norström K, Holte J, Landin-Wilhelmsen K, Dahlgren E, Landén M. Sexuality and psychological wellbeing in women with polycystic ovary syndrome compared with healthy controls. Eur J Obstet Gynecol Reprod Biol. (2011) 155:161-5. doi: 10.1016/j.ejogrb.2010.12.012

56. Elsenbruch S, Hahn S, Kowalsky D, Offner AH, Schedlowski M, Mann $\mathrm{K}$, et al. Quality of life, psychosocial well-being, and sexual satisfaction in women with polycystic ovary syndrome. J Clin Endocrinol Metab. (2003) 88:5801-7. doi: 10.1210/jc.2003-030562

57. Noroozzadeh M, Tehrani FR, Mobarakabadi SS, Farahmand M, Dovom MR. Sexual function and hormonal profiles in women with and without polycystic ovary syndrome: a population-based study. Int J Impot Res. (2017) 29:1-6. doi: 10.1038/ijir.2016.35

58. Kowalczyk R, Skrzypulec-Plinta V, Nowosielski K. Sexuality in women with polycystic ovary syndrome. Ginekol Pol. (2015) 86:100-6. doi: 10.17772/gp/1995

59. Zueff LN, Lara LA, Vieira CS, de Paula Martins W, Ferriani RA. Body composition characteristics predict sexual functioning in obese women with or without PCOS. J Sex Marital Ther. (2015) 41:22737. doi: 10.1080/0092623X.2013.864369

60. Ferraresi SR, Lara LA, Reis RM, Rosa e Silva AC. Changes in sexual function among women with polycystic ovary syndrome: a pilot study. J Sex Med. (2013) 10:467-73. doi: 10.1111/jsm.12011

61. Ercan CM, Coksuer H, Aydogan U, Alanbay I, Keskin U, Karasahin $\mathrm{KE}$, et al. Sexual dysfunction assessment and hormonal correlations in patients with polycystic ovary syndrome. Int J Impot Res. (2013) 25:12732. doi: 10.1038/ijir.2013.2

62. Stovall DW, Scriver JL, Clayton AH, Williams CD, Pastore LM. Sexual function in women with polycystic ovary syndrome. J Sex Med. (2012) 9:224-30. doi: 10.1111/j.1743-6109.2011.02539.x

63. Battaglia C, Nappi RE, Mancini F, Cianciosi A, Persico N, Busacchi P, et al. PCOS, sexuality, and clitoral vascularisation: a pilot study. J Sex Med. (2008) 5:2886-94. doi: 10.1111/j.1743-6109.2008.01010.x

64. Diamond MP, Legro RS, Coutifaris C, Alvero R, Robinson RD, Casson PA, et al. Sexual function in infertile women with polycystic ovary syndrome and unexplained infertility. Am J Obstet Gynecol. (2017) 217:191.e1191.e19. doi: 10.1016/j.ajog.2017.04.034

65. Eftekhar T, Sohrabvand F, Zabandan N, Shariat M, Haghollahi F, GhahghaeiNezamabadi A. Sexual dysfunction in patients with polycystic ovary syndrome and its affected domains. Iran J Reprod Med. (2014) 12:539-46.

66. Rellini AH, Stratton N, Tonani S, Santamaria V, Brambilla E, Nappi RE. Differences in sexual desire between women with clinical versus biochemical signs of hyperandrogenism in polycystic ovarian syndrome. Horm Behav. (2013) 63:65-71. doi: 10.1016/j.yhbeh.2012.10.013

67. De Frène V, Verhofstadt L, Loeys T, Stuyver I, Buysse A, De Sutter P. Sexual and relational satisfaction in couples where the woman has polycystic ovary syndrome: a dyadic analysis. Hum Reprod Oxf Engl. (2015) 30:62531. doi: 10.1093/humrep/deu342

68. Christ JP, Gunning MN, Meun C, Eijkemans MJC, van Rijn BB, Bonsel GJ, et al. Pre-conception characteristics predict obstetrical and neonatal outcomes in women with polycystic ovary syndrome. J Clin Endocrinol Metab. (2019) 104:809-18. doi: 10.1210/jc.2018-01787

69. Abbott DH, Barnett DK, Bruns CM, Dumesic DA. Androgen excess fetal programming of female reproduction: a developmental aetiology for polycystic ovary syndrome? Hum Reprod Update. (2005) 11:35774. doi: 10.1093/humupd/dmi013

70. Day F, Karaderi T, Jones MR, Meun C, He C, Drong A, et al. Large-scale genome-wide meta-analysis of polycystic ovary syndrome suggests shared genetic architecture for different diagnosis criteria. PLoS Genet. (2019) 15:e1008517. doi: 10.1371/journal.pgen.1007813

71. Dumesic DA, Hoyos LR, Chazenbalk GD, Naik R, Padmanabhan V, Abbott $\mathrm{DH}$. Mechanisms of intergenerational transmission of polycystic ovary syndrome. Reproduction. (2020) 159:R1-R13. doi: 10.1530/REP-19-0197

72. Filippou P, Homburg R. Is foetal hyperexposure to androgens a cause of PCOS? Hum Reprod Update. (2017) 23:42132. doi: 10.1093/humupd/dmx013

73. Risal S, Pei Y, Lu H, Manti M, Fornes R, Pui HP, et al. Prenatal androgen exposure and transgenerational susceptibility to polycystic ovary syndrome. Nat Med. (2019) 25:1894-904. doi: 10.1038/s41591-019-0666-1 
74. Escobar-Morreale HF. Polycystic ovary syndrome: definition, aetiology, diagnosis and treatment. Nat Rev Endocrinol. (2018) 14:270-84. doi: 10.1038/nrendo.2018.24

75. Yessoufou A, Moutairou K. Maternal diabetes in pregnancy: early and longterm outcomes on the offspring and the concept of "metabolic memory". Exp Diabetes Res. (2011) 2011:218598. doi: 10.1155/2011/218598

76. Gunning MN, Sir Petermann T, Crisosto N, van Rijn BB, de Wilde MA, Christ JP, et al. Cardiometabolic health in offspring of women with PCOS compared to healthy controls: a systematic review and individual participant data meta-analysis. Hum Reprod Update. (2020) 26:10317. doi: 10.1093/humupd/dmz036

77. Welt CK, Carmina E. Clinical review: lifecycle of polycystic ovary syndrome (PCOS): from in utero to menopause. J Clin Endocrinol Metab. (2013) 98:4629-38. doi: 10.1210/jc.2013-2375

78. Bell GA, Sundaram R, Mumford SL, Park H, Mills J, Bell EM, et al. Maternal polycystic ovarian syndrome and early offspring development. Hum Reprod. (2018) 33:1307-15. doi: 10.1093/humrep/dey087

79. Dewailly D, Pigny P, Soudan B, Catteau-Jonard S, Decanter C, Poncelet E, et al. Reconciling the definitions of polycystic ovary syndrome: the ovarian follicle number and serum anti-müllerian hormone concentrations aggregate with the markers of hyperandrogenism. J Clin Endocrinol Metab. (2010) 95:4399-405. doi: 10.1210/jc.2010-0334

80. Sir-Petermann T, Codner E, Maliqueo M, Echiburú B, Hitschfeld C, Crisosto N, et al. Increased anti-Müllerian hormone serum concentrations in prepubertal daughters of women with polycystic ovary syndrome. J Clin Endocrinol Metab. (2006) 91:3105-9. doi: 10.1210/jc.2005-2693

81. Sir-Petermann T, Márquez L, Cárcamo M, Hitschfeld C, Codner E, Maliqueo $\mathrm{M}$, et al. Effects of birth weight on anti-mullerian hormone serum concentrations in infant girls. J Clin Endocrinol Metab. (2010) 95:90310. doi: 10.1210/jc.2009-1771

82. Legro RS, Roller RL, Dodson WC, Stetter CM, Kunselman AR, Dunaif A. Associations of birthweight and gestational age with reproductive and metabolic phenotypes in women with polycystic ovarian syndrome and their first-degree relatives. J Clin Endocrinol Metab. (2010) 95:78999. doi: 10.1210/jc.2009-1849

83. Davies MJ, March WA, Willson KJ, Giles LC, Moore VM. Birthweight and thinness at birth independently predict symptoms of polycystic ovary syndrome in adulthood. Hum Reprod. (2012) 27:1475-80. doi: 10.1093/humrep/des027

84. Vanky E, Engen Hanem LG, Abbott DH. Children born to women with polycystic ovary syndrome-short- and longterm impacts on health and development. Fertil Steril. (2019) 111:1065-75. doi: 10.1016/j.fertnstert.2019.03.015

85. Legro RS, Kunselman AR, Stetter CM, Gnatuk CL, Estes SJ, Brindle E, et al. Normal pubertal development in daughters of women with PCOS: a controlled study. J Clin Endocrinol Metab. (2017) 102:12231. doi: 10.1210/jc.2016-2707

86. Kent SC, Gnatuk CL, Kunselman AR, Demers LM, Lee PA, Legro RS. Hyperandrogenism and hyperinsulinism in children of women with polycystic ovary syndrome: a controlled study. J Clin Endocrinol Metab. (2008) 93:1662-9. doi: 10.1210/jc.2007-1958

87. De Zegher F, López-Bermejo A, Ibáñez L. Central obesity, faster maturation, and 'PCOS' in girls. Trends Endocrinol Metab. (2018) 29:81518. doi: 10.1016/j.tem.2018.09.005

88. Torchen LC, Idkowiak J, Fogel NR, O'Neil DM, Shackleton CH, Arlt W, et al. Evidence for increased $5 \alpha$-reductase activity during early childhood in daughters of women with polycystic ovary syndrome. J Clin Endocrinol Metab. (2016) 101:2069-75. doi: 10.1210/jc.2015-3926

89. Wu C, Wei K, Jiang Z. $5 \alpha$-reductase activity in women with polycystic ovary syndrome: a systematic review and meta-analysis. Reprod Biol Endocrinol. (2017) 15:21. doi: 10.1186/s12958-017-0242-9

90. Azziz, R. Polycystic ovary syndrome. Obstet Gynecol. (2018) 132:32136. doi: 10.1097/AOG.0000000000002698

91. Ibáñez L, Oberfield SE, Witchel S, Auchus RJ, Chang RJ, Codner E, et al. An international consortium update: pathophysiology, diagnosis, and treatment of polycystic ovarian syndrome in adolescence. Horm Res Paediatr. (2017) 88:371-95. doi: 10.1159/000479371
92. Witchel SF, Oberfield SE, Peña AS. Polycystic ovary syndrome: pathophysiology, presentation, and treatment with emphasis on adolescent girls. J Endocr Soc. (2019) 3:1545-73. doi: 10.1210/js.2019-00078

93. Melnik, BC. Acne vulgaris: the metabolic syndrome of the pilosebaceous follicle. Clin Dermatol. (2018) 36:2940. doi: 10.1016/j.clindermatol.2017.09.006

94. Teede HJ, Misso ML, Costello MF, Dokras A, Laven J, Moran L, et al. Recommendations from the international evidence-based guideline for the assessment and management of polycystic ovary syndrome. Hum Reprod. (2019) 33:1602-18. doi: 10.1093/humrep/dey256

95. Kjerulff LE, Sanchez-Ramos L, Duffy D. Pregnancy outcomes in women with polycystic ovary syndrome: a metaanalysis. Am J Obstet Gynecol. (2011) 204:558.e1-6. doi: 10.1016/j.ajog.2011.03.021

96. Katulski K, Czyzyk A, Podfigurna-Stopa A, Genazzani AR, Meczekalski B. Pregnancy complications in polycystic ovary syndrome patients. Gynecol Endocrinol. (2015) 31:87-91. doi: 10.3109/09513590.2014.974535

97. Mustaniemi S, Vääräsmäki $M$, Eriksson JG, Gissler M, Laivuori $H$, Ijäs $H$, et al. Polycystic ovary syndrome and risk factors for gestational diabetes. Endocr Connect. (2018) 7:859-69. doi: 10.1530/EC-18-0076

98. Wang Q, Würtz P, Auro K, Mäkinen V-P, Kangas AJ, Soininen P, et al. Metabolic profiling of pregnancy: cross-sectional and longitudinal evidence. BMC Med. (2016) 14:205. doi: 10.1186/s12916-016-0733-0

99. Formoso G, Baldassarre MPA, Ginestra F, Carlucci MA, Bucci I, Consoli A. Inositol and antioxidant supplementation: safety and efficacy in pregnancy. Diabetes Metab Res Rev. (2019) 35:e3154. doi: 10.1002/dmrr.3154

100. Wilcox G. Impact of pregnancy on inborn errors of metabolism. Rev Endocr Metab Disord. (2018) 19:13-33. doi: 10.1007/s11154-018-9455-2

101. Vitacolonna E, Succurro E, Lapolla A, Scavini M, Bonomo M, Di Cianni G, et al. Guidelines for the screening and diagnosis of gestational diabetes in Italy from 2010 to 2019: critical issues and the potential for improvement. Acta Diabetol. (2019) 56:1159-67. doi: 10.1007/s00592-019-01397-4

102. Xu Y, Zhang M, Zhang J, Sun Z, Ran L, Ban Y, et al. Differential intestinal and oral microbiota features associated with gestational diabetes and maternal inflammation. Am J Physiol Endocrinol Metab. (2019) 319:E247E53. doi: 10.1152/ajpendo.00266.2019

103. Cui M, Qi C, Yang L, Zhang M, Wang H, She G, et al. A pregnancy complication-dependent change in SIgA-targeted microbiota during third trimester. Food Funct. (2020) 11:1513-24. doi: 10.1039/C9FO02919B

104. Ponzo V, Ferrocino I, Zarovska A, Amenta MB, Leone F, Monzeglio $\mathrm{C}$, et al. The microbiota composition of the offspring of patients with gestational diabetes mellitus (GDM). PLoS ONE. (2019) 14:e0226545. doi: 10.1371/journal.pone.0226545

105. Calogero AE, Calabrò V, Catanuso $\mathrm{M}$, Condorelli RA, La Vignera $\mathrm{S}$. Understanding polycystic ovarian syndrome pathogenesis: an updated of its genetic aspects. J Endocrinol Invest. (2011) 34:630-44. doi: 10.3275/7746

106. Cannarella R, Condorelli RA, Mongiò LM, La Vignera S, Calogero AE. Does a male polycystic ovarian syndrome equivalent exist? J Endocrinol Invest. (2018) 41:49-57. doi: 10.1007/s40618-017-0728-5

107. Norman RJ, Masters S, Hague W. Hyperinsulinemia is common in family members of women with polycystic ovary syndrome. Fertil Steril. (1996) 66:942-7. doi: 10.1016/S0015-0282(16)58687-7

108. Benítez R, Sir-Petermann T, Palomino A, Angel B, Maliqueo M, Pérez F, et al. Prevalence of metabolic disorders among family members of patients with polycystic ovary syndrome. Rev Med Chil. (2001) 129:70712. doi: $10.4067 / \mathrm{S} 0034-98872001000700001$

109. Yilmaz M, Bukan N, Ersoy R, Karakoç A, Yetkin I, Ayvaz G, et al. Glucose intolerance, insulin resistance and cardiovascular risk factors in first degree relatives of women with polycystic ovary syndrome. Hum Reprod. (2005) 20:2414-20. doi: 10.1093/humrep/dei070

110. Kaushal R, Parchure N, Bano G, Kaski JC, Nussey SS. Insulin resistance and endothelial dysfunction in the brothers of Indian subcontinent Asian women with polycystic ovaries. Clin Endocrinol. (2004) 60:3228. doi: 10.1111/j.1365-2265.2004.01981.x

111. Legro RS, Kunselman AR, Demers L, Wang SC, Bentley-Lewis R, Dunaif A. Elevated dehydroepiandrosterone sulfate levels as the reproductive phenotype in the brothers of women with polycystic ovary syndrome. J Clin Endocrinol Metab. (2002) 87:2134-8. doi: 10.1210/jcem.87.5.8387 
112. Lenarcik A, Bidzinska-Speichert B, Tworowska-Bardzinska U, Krepuła K. Hormonal abnormalities in first-degree relatives of women with polycystic ovary syndrome (PCOS). Endokrynologia Polska. (2011) 62:129-33.

113. Torchen LC, Kumar A, Kalra B, Savjani G, Sisk R, Legro RS, et al. Increased antimullarian hormone levels and other reproductive endocrine changes in adult male relatives of women with polycystic ovary syndrome. Fertil Steril. (2016) 106:50-55. doi: 10.1016/j.fertnstert.2016.03.029

114. Liu DM, Torchen LC, Sung Y, Paparodis R, Legro RS, Grebe SK, et al. Evidence for gonadotrophin secretory and steroidogenic abnormalities in brothers of women with polycystic ovary syndrome. Hum Reprod. (2014) 29:2764-72. doi: 10.1093/humrep/deu282

115. Hamilton JB. Patterned loss of hair in man: types and incidence. Ann NY Acad Sci. (1951) 53:708-28. doi: 10.1111/j.1749-6632.1951.tb31971.x

116. Norwood OT. Male pattern baldness: classification and incidence. South Med J. (1975) 68:1359-65. doi: 10.1097/00007611-197511000-00009

117. Lunde O, Magnus P, Sandvik L, Høglo S. Familial clustering in the polycystic ovarian syndrome. Gynecol Obstet Invest. (1989) 28:2330. doi: 10.1159/000293493

118. Dusková M, Cermáková I, Hill M, Vanková M, Sámalíková P, Stárka L. What may be the markers of the male equivalent of polycystic ovary syndrome? Physiol Res. (2004) 53:287-95.

119. Cannarella R, La Vignera S, Condorelli RA, Calogero AE. Glycolipid and hormonal profiles in young men with early-onset androgenetic alopecia: a meta-analysis. Sci Rep. (2017) 7:7801. doi: 10.1038/s41598-017-08528-3

120. Lesko SM, Rosenberg L, Shapiro S. A case-control study of baldness in relation to myocardial infarction in men. JAMA. (1993) 269:9981003. doi: 10.1001/jama.1993.03500080046030

121. Lotufo PA, Chae CU, Ajani UA, Hennekens CH, Manson JE. Male pattern baldness and coronary heart disease: the physicians' health study. Arch Intern Med. (2000) 160:165-71. doi: 10.1001/archinte.160.2.165

122. Herrera CR, D’ Agostino RB, Gerstman BB, Bosco LA, Belanger AJ. Baldness and coronary heart disease rates in men from the framingham study. Am J Epidemiol. (1995) 142:828-33. doi: 10.1093/oxfordjournals.aje.a117722

123. Ford ES, Freedman DS, Byers T. Baldness and ischemic heart disease in a national sample of men. Am J Epidemiol. (1996) 143:6517. doi: 10.1093/oxfordjournals.aje.a008797

124. Trieu N, Eslick GD. Alopecia and its association with coronary heart disease and cardiovascular risk factors: a meta-analysis. Int J Cardiol. (2014) 176:687-95. doi: 10.1016/j.ijcard.2014.07.079

125. Su LH, Chen LS, Lin SC, Chen HH. Association of androgenetic alopecia with mortality from diabetes mellitus and heart disease. JAMA Dermatol. (2013) 149:601-6. doi: 10.1001/jamadermatol.2013.130

126. D’ Anna R, Scilipoti A, Giordano D, Caruso C, Cannata ML, Interdonato $\mathrm{ML}$, et al. Myo-Inositol supplementation and onset of gestational diabetes mellitus in pregnant women with a family history of type 2 diabetes: a prospective, randomized, placebo-controlled study. Diabetes Care. (2013) 36:854e7. doi: $10.2337 / \mathrm{dc} 12-1371$

127. Tay CT, Joham AE, Hiam DS, Gadalla MA, Pundir J, Thangaratinam S, et al. Pharmacological and surgical treatment of nonreproductive outcomes in polycystic ovary syndrome: an overview of systematic reviews. Clin Endocrinol. (2018) 89:535-53. doi: 10.1111/cen.13753

128. Amiri M, Ramezani Tehrani F, Nahidi F, Kabir A, Azizi F. Comparing the effects of combined oral contraceptives containing progestins with low androgenic and antiandrogenic activities on the hypothalamic-pituitarygonadal axis in patients with polycystic ovary syndrome: systematic review and meta-analysis. JMIR Res Protoc. (2018) 7:e113. doi: 10.2196/resprot.9024

129. Menshawy A, Ismail A, Abdel-Maboud M, El-Din AA, Elgebaly A, Gadelkarim M, et al. Effect of chlormadinone acetate versus drospirenonecontaining oral contraceptives on the endocrinal features of women with polycystic ovary syndrome: systematic review and meta-analysis of randomized clinical trials. J Gynecol Obstet Hum Reprod. (2019) 48:76370. doi: 10.1016/j.jogoh.2019.03.025

130. Gao YF, Zhang MN, Wang TX, Wu TC, Ai RD, Zhang ZS. Hypoglycemic effect of D-chiro-inositol in type 2 diabetes mellitus rats through the PI3K/Akt signaling pathway. Mol Cell Endocrinol. (2016) 433:2634. doi: 10.1016/j.mce.2016.05.013

131. Naderpoor N, Shorakae S, De Courten B, Misso ML, Moran LJ, Teede HJ. Metformin and lifestyle modification in polycystic ovary syndrome: systematic review and meta-analysis. Hum Reprod Update. (2016) 22:4089. doi: 10.1093/humupd/dmv063

132. Bharti K, Kalra S, Sharma JB. The inositols and polycystic ovary syndrome. Indian J Endocrinol Metab. (2017) 20:720-4. doi: 10.4103/2230-8210.189231

133. Wang A, Mo T, Li Q, Shen C, Liu M. The effectiveness of metformin, oral contraceptives, and lifestyle modification in improving the metabolism of overweight women with polycystic ovary syndrome: a network metaanalysis. Endocrine. (2019) 64:220-32. doi: 10.1007/s12020-019-01860-w

134. Panda SR, Jain M, Jain S, Saxena R, Hota S. Effect of orlistat versus metformin in various aspects of polycystic ovarian syndrome: a systematic review of randomized control trials. J Obstet Gynaecol India. (2018) 68:33643. doi: 10.1007/s13224-018-1140-6

135. Han Y, Li Y, He B. GLP-1 receptor agonists versus metformin in PCOS: a systematic review and meta-analysis. Reprod Biomed Online. (2019) 39:33242. doi: 10.1016/j.rbmo.2019.04.017

136. Laganà AS, Rossetti $\mathrm{P}$, Buscema $\mathrm{M}$, La Vignera S, Condorelli RA, Gullo G, et al. Metabolism and ovarian function in PCOS women: a therapeutic approach with inositols. Int $J$ Endocrinol. (2016) 2016:6306410. doi: 10.1155/2016/6306410

137. Croze ML, Soulage CO. Potential role and therapeutic interests of myo-inositol in metabolic diseases. Biochimie. (2013) 95:1811-27. doi: 10.1016/j.biochi.2013.05.011

138. Larner J. D-chiro-inositol-its functional role in insulin action and its deficit in insulin resistance. Int J Exp Diabetes Res. (2002) 3:4760. doi: 10.1080/15604280212528

139. Nestler JE, Unfer V. Reflections on inositol(s) for PCOS therapy: steps toward success. Gynecol Endocrinol. (2015) 31:501-5. doi: 10.3109/09513590.2015.1054802

140. Laganà AS, Garzon S, Casarin J, Franchi M, Ghezzi F. Inositol in polycystic ovary syndrome: restoring fertility through a pathophysiology-based approach. Trends Endocrinol Metab. (2018) 29:768-80. doi: 10.1016/j.tem.2018.09.001

141. Carlomagno G, Unfer V, Benvenga S, Nestler JE. Myo-inositol: with or without. Endocrine J. (2016) 62:297-8. doi: 10.1507/endocrj.EJ14-0566

142. Condorelli RA, Calogero AE, Di Mauro M, Mongioi LM, Cannarella R, Rosta G, et al. Androgen excess and metabolic disorders in women with PCOS: beyond the body mass index. J Endocrinol Invest. (2018) 41:3838. doi: 10.1007/s40618-017-0762-3

143. Condorelli RA, Calogero AE, Di Mauro M, La Vignera S. PCOS and diabetes mellitus: from insulin resistance to altered beta pancreatic function, a link in evolution. Gynecol Endocrinol. (2017) 33:6657. doi: 10.1080/09513590.2017.1342240

144. Rahimlou M, Asadi M, Banaei Jahromi N, Mansoori A. Alpha-lipoic acid (ALA) supplementation effect on glycemic and inflammatory biomarkers: a systematic review and meta-analysis. Clin Nutr ESPEN. (2019) 32:1628. doi: 10.1016/j.clnesp.2019.03.015

145. Padmalayam I, Hasham S, Saxena U, Pillarisetti S. Lipoic acid synthase (LASY): a novel role in inflammation, mitochondrial function, and insulin resistance. Diabetes. (2009) 58:600-8. doi: 10.2337/db08-0473

146. Namazi N, Larijani B, Azadbakht L. Alpha-lipoic acid supplement in obesity treatment: a systematic review and meta-analysis of clinical trials. Clin Nutr. (2018) 37:419-28. doi: 10.1016/j.clnu.2017.06.002

147. Pershadsingh HA. Alpha-lipoic acid: physiologic mechanisms and indications for the treatment of metabolic syndrome. Expert Opin Investig Drugs. (2007) 16:291-302. doi: 10.1517/13543784.16.3.291

148. Haghighatdoost F, Gholami A, Hariri M. Alpha-lipoic acid effect on leptin and adiponectin concentrations: a systematic review and meta-analysis of randomized controlled trials. Eur J Clin Pharmacol. (2020) 76:64957. doi: 10.1007/s00228-020-02844-w

149. Konrad D. Utilization of the insuli-signaling network in the metabolic actions of $\alpha$-lipoic acid- reduction or oxidation? Antioxid Redox Sign. (2005) 7:1032-9. doi: 10.1089/ars.2005.7.1032

150. Golbidi S, Badran M, Laher I. Diabetes and alpha lipoic acid. Front Pharmacol. (2011) 2:69. doi: 10.3389/fphar.2011.00069

151. Di Nicuolo F, D’ Ippolito S, Castellani R, Rossi ED, Masciullo V, Specchia $\mathrm{M}$, et al. Effect of alpha-lipoic acid and myoinositol on endometrial inflammasome from recurrent pregnancy loss women. Am J Reprod Immunol. (2019) 82:e13153. doi: 10.1111/aji.13153 
152. Cianci A, Panella M, Fichera M, Falduzzi C, Bartolo M, Caruso S. Dchiro-inositol and alpha lipoic acid treatment of metabolic and menses disorders in women with PCOS. Gynecol Endocrinol. (2015) 31:4836. doi: 10.3109/09513590.2015.1014784

153. Masharani U, Gjerde C, Evans JL, Youngren JF, Goldfine ID. Effects of controlled-release alpha lipoic acid in lean, nondiabetic patients with polycystic ovary syndrome. J Diabetes Sci Technol. (2010) 4:35964. doi: $10.1177 / 193229681000400218$

154. De Cicco S, Immediata V, Romualdi D, Policola C, Tropea A, Di Florio C, et al. Myoinositol combined with alpha-lipoic acid may improve the clinical and endocrine features of polycystic ovary syndrome through an insulin-independent action. Gynecol Endocrinol. (2017) 33:698701. doi: 10.1080/09513590.2017.1313972

155. Gennazzani AD, Despini G, Santagni S, Prati A, Rattighieri E, Chierchia E, et al. Effects of a combination of alpha lipoic acid and myo-inoitol on insulin dynamics in overweight/obese patients with PCOS. Endocrinol Metab Synd. (2014) 3:3. doi: 10.4172/2161-1017.1000140

156. Genazzani AD, Shefer K, Della Casa D, Prati A, Napolitano A, Manzo A, et al. Modulatory effects of alpha-lipoic acid (ALA) administration on insulin sensitivity in obese PCOS patients. J Endocrinol Invest. (2018) 41:58390. doi: 10.1007/s40618-017-0782-z

157. Colazingari S, Treglia M, Najjar R, Bevilacqua A. The combined therapy myo-inositol plus D-chiro-inositol, rather than D-chiro-inositol, is able to improve IVF outcomes: results from a randomized controlled trial. Arch Gynecol Obstet. (2013) 288:1405-11. doi: 10.1007/s00404-0 13-2855-3

158. Tang T, Lord JM, Norman RJ, Balen AH. Insulin-sensitising drugs (metformin, rosiglitazone, pioglitazone, D-chiroinositol) for women with polycystic ovary syndrome, oligo amenorrhoea and subfertility. Cochrane Database Syst Rev. (2012) 11:CD003053. doi: 10.1002/14651858.CD003053.pub5

159. Palomba S, Falbo A, Carrillo L, Villani MT, Orio F, Russo T, et al. Metformin reduces risk of ovarian hyperstimulation syndrome in patients with polycystic ovary syndrome during gonadotropin-stimulated in vitro fertilization cycles: a randomized, controlled trial. Fertil Steril. (2011) 96:1384-90. doi: 10.1016/j.fertnstert.2011.09.020

160. Papaleo E, Unfer V, Baillergeon JP, Fusi F, Occhi F, de Santis L. Myo-inositol may improve oocyte quality in intracytoplasmatic sperm injection cycles. A prospective, controlled, randomized trial. Fertil Steril. (2009) 91:17504. doi: 10.1016/j.fertnstert.2008.01.088

161. Ciotta L, Stracquadanio M, Pagano I, Carbonaro A, Palumbo M, Gulino F. Effects of myoinositol supplementation on oocyte's quality in PCOS patients: a double blind trial. Eur Rev Med Pharmacol Sci. (2011) 15:509-14.

162. Truong T, Gardner DK. Antioxidants improve IVF outcome and subsequent embryo development in the mouse. Hum Reprod. (2017) 32:240413. doi: 10.1093/humrep/dex330

163. Rago R, Marcucci I, Leto G, Caponecchia L, Salacone P, Bonanni P, et al. Effect of myo-inositol and alpha-lipoic acid on oocyte quality in polycystic ovary syndrome non-obese women undergoing in vitro fertilization: a pilot study. J Biol Regul Homeost Agents. (2015) 29:913-23.

164. Ciotta L, Pagano I, Stracquadanio M, Formuso C. Polycystic ovarian syndrome incidence in young women with non-alcoholic fatty liver disease. Minerva Ginecol. (2011) 63:429-37.

165. Cree-Green M, Bergman BC, Coe GV, Newnes L, Baumgartner AD, Bacon $\mathrm{S}$, et al. Hepatic steatosis is common in adolescents with obesity and PCOS and relates to de novo lipogenesis but not insulin resistance. Obesity. (2016) 24:2399-406. doi: 10.1002/oby.21651

166. Grasselli E, Baldini F, Vecchione G, Oliveira PJ, Sardão VA, Voci $A$, et al. Excess fructose and fatty acids trigger a model of non alcoholic fatty liver disease progression in vitro: protective effect of the flavonoid silybin. Int J Mol Med. (2019) 44:705-12. doi: 10.3892/ijmm. 2019.4234

167. Lama S, Vanacore D, Diano N, Nicolucci C, Errico S, Dallio M, et al. Ameliorative effect of Silybin on bisphenol A induced oxidative stress, cell proliferation and steroid hormones oxidation in HepG2 cell cultures. Sci Rep. (2019) 9:3228. doi: 10.1038/s41598-019-40105-8

168. Vecchione G, Grasselli E, Cioffi F, Baldini F, Oliveira PJ, Sardão VA, et al. The nutraceutic Silybin counteracts excess lipid accumulation and ongoing oxidative stress in an in vitro model of non-alcoholic fatty liver disease progression. Front Nutr. (2017) 4:42. doi: 10.3389/fnut.2017. 00042

169. Federico A, Dallio M, Masarone M, Gravina AG, Di Sarno R, Tuccillo $C$, et al. Evaluation of the effect derived from silybin with vitamin $\mathrm{d}$ and vitamin e administration on clinical, metabolic, endothelial dysfunction, oxidative stress parameters, and serological worsening markers in nonalcoholic fatty liver disease patients. Oxid Med Cell Longev. (2019) 2019:8742075. doi: 10.1155/2019/8742075

170. Tran HT, Liong S, Lim R, Barker G, Lappas M. Resveratrol ameliorates the chemical and microbial induction of inflammation and IR in human placenta, adipose tissue and skeletal muscle. PLoS ONE. (2017) 12:e173373. doi: 10.1371/journal.pone. 0173373

171. Diwaker A, Kishore D. Evaluation of plasma homocysteine levels in patients of PCOS. J Assoc Physicians India. (2018) 66:17-20.

172. Karadeniz M, Erdogan M, Ayhan Z, Yalcin M, Olukman M, Cetinkalp S, et al. Effect Of G2706A and G1051A polymorphisms of the ABCA1 gene on the lipid, oxidative stress and homocystein levels in Turkish patients with polycystic ovary syndrome. Lipids Health Dis. (2011) 10:193. doi: 10.1186/1476-511X-10-193

173. Asanidze E, Kristesashvili J, Andguladze S. Correlation between levels of homocysteine, anti-müllerian hormone and insulin resistance in PCOS patients with recurrent miscarriage. Georgian Med News. (2019) 290:25-9.

174. Piazzolla G, Candigliota M, Fanelli M, Castrovilli A, Berardi E, Antonica G, et al. Hyperhomocysteinemia is an independent risk factor of atherosclerosis in patients with metabolic syndrome. Diabetol Metab Syndr. (2019) 11:87. doi: 10.1186/s13098-019-0484-0

175. Singh Y, Samuel VP, Dahiya S, Gupta G, Gillhotra R, Mishra $A$, et al. Combinational effect of angiotensin receptor blocker and folic acid therapy on uric acid and creatinine level in hyperhomocysteinemia-associated hypertension. Biotechnol Appl Biochem. (2019) 66:715-19. doi: 10.1002/bab.1799

176. Totzeck M, Mincu RI, Rassaf T. Cardiovascular adverse events in patients with cancer treated with bevacizumab: a meta-analysis of more than 20 000 patients. J Am Heart Assoc. (2017) 6:e006278. doi: 10.1161/JAHA.117. 006278

177. Shepherd E, Gomersall JC, Tieu J, Han S, Crowther CA, Middleton P. Combined diet and exercise interventions for preventing gestational diabetes mellitus. Cochrane Database Syst Rev. (2017) 2017:CD010443. doi: 10.1002/14651858.CD010443.pub3

178. Morley LC, Tang T, Yasmin E, Norman RJ, Balen AH. Insulinsensitising drugs (metformin, rosiglitazone, pioglitazone, Dchiro-inositol) for women with polycystic ovary syndrome, oligo amenorrhoea and subfertility. Cochrane Database Syst Rev. (2017) 11:CD003053. doi: 10.1002/14651858.CD00 3053.pub6

179. Showell MG, Mackenzie-Proctor R, Jordan V, Hodgson R, Farquhar C. Inositol for subfertile women with polycystic ovary syndrome. Cochrane Database Syst Rev. (2018) 2018:CD012378. doi: 10.1002/14651858.CD012378.pub2

180. Ferrari F, Facchinetti F, Ontiveros AE, Roberts RP, Saade MM, Blackwell $\mathrm{SC}$, et al. The effect of combined inositol supplementation on maternal metabolic profile in pregnancies complicated by metabolic syndrome and obesity. Am J Obstet Gynecol. (2016) 215:503.e1-8. doi: 10.1016/j.ajog.2016. 05.038

181. Celentano C, Matarrelli B, Mattei PA, Pavone G, Vitacolonna E, Liberati M. Myo-inositol supplementation to prevent gestational diabetes mellitus. Curr Diab Rep. (2016) 16:30. doi: 10.1007/s11892-016-0726-6

182. D’Anna R, Di Benedetto V, Rizzo P, Raffone E, Interdonato ML, Corrado F, et al. Myo-inositol may prevent gestational diabetes in PCOS women. Gynecol Endocrinol. (2012) 28:440-2. doi: 10.3109/09513590.2011. 633665

183. Ponzo V, Fedele D, Goitre I, Leone F, Lezo A, Monzeglio C, et al. Diet-Gut microbiota interactions and gestational diabetes mellitus (GDM). Nutrients. (2019) 11:330. doi: 10.3390/nu11020330

184. Kim JH, Kang MJ, Choi HN, Jeong SM, Lee YM, Kim JI, et al. Quercetin attenuates fasting and postprandial hyperglycemia 
in animal models of diabetes mellitus. Nutr Res Pract. (2011) 5:107-11. doi: 10.4162/nrp.2011.5.2.107

185. Günalan E, Yaba A, Yilmaz B. The effect of nutrient supplementation in the management of polycystic ovary syndrome-associated metabolic dysfunctions: a critical review. J Turk Ger Gynecol Assoc. (2018) 19:22032. doi: 10.4274/jtgga.2018.0077

186. Zhang J, Ma S, Wu S, Guo C, Long S, Tan H. Effects of probiotic supplement in pregnant women with gestational diabetes mellitus: a systematic review and meta-analysis of randomized controlled trials. J Diabetes Res. (2019) 2019:5364730. doi: 10.1155/2019/5364730

187. Malvasi A, Kosmas I, Mynbaev OA, Sparic R, Gustapane S, Guido M, et al. Can trans resveratrol plus d-chiro-inositol and myo-inositol improve maternal metabolic profile in overweight pregnant patients? Clin Ter. (2017) 168:e240-7. doi: 10.7417/T.2017.2013
Conflict of Interest: The authors declare that the research was conducted in the absence of any commercial or financial relationships that could be construed as a potential conflict of interest.

The handling editor declared a past co-authorship with the authors RR, AC, and AF.

Copyright (C) 2020 Aversa, La Vignera, Rago, Gambineri, Nappi, Calogero and Ferlin. This is an open-access article distributed under the terms of the Creative Commons Attribution License (CC BY). The use, distribution or reproduction in other forums is permitted, provided the original author(s) and the copyright owner(s) are credited and that the original publication in this journal is cited, in accordance with accepted academic practice. No use, distribution or reproduction is permitted which does not comply with these terms. 